\title{
Synapse development and maturation at the drosophila neuromuscular junction
}

\author{
Vivian T. Chou ${ }^{\dagger}$, Seth A. Johnson ${ }^{* \dagger}$ (D) and David Van Vactor ${ }^{*}$
}

\begin{abstract}
Synapses are the sites of neuron-to-neuron communication and form the basis of the neural circuits that underlie all animal cognition and behavior. Chemical synapses are specialized asymmetric junctions between a presynaptic neuron and a postsynaptic target that form through a series of diverse cellular and subcellular events under the control of complex signaling networks. Once established, the synapse facilitates neurotransmission by mediating the organization and fusion of synaptic vesicles and must also retain the ability to undergo plastic changes. In recent years, synaptic genes have been implicated in a wide array of neurodevelopmental disorders; the individual and societal burdens imposed by these disorders, as well as the lack of effective therapies, motivates continued work on fundamental synapse biology. The properties and functions of the nervous system are remarkably conserved across animal phyla, and many insights into the synapses of the vertebrate central nervous system have been derived from studies of invertebrate models. A prominent model synapse is the Drosophila melanogaster larval neuromuscular junction, which bears striking similarities to the glutamatergic synapses of the vertebrate brain and spine; further advantages include the simplicity and experimental versatility of the fly, as well as its century-long history as a model organism. Here, we survey findings on the major events in synaptogenesis, including target specification, morphogenesis, and the assembly and maturation of synaptic specializations, with a emphasis on work conducted at the Drosophila neuromuscular junction.
\end{abstract}

Keywords: Drosophila melanogaster, Synapse, Neuromuscular junction, Bouton addition, Synaptic plasticity, Presynaptic active zone, Cell-adhesion molecules, Trans-synaptic signaling

\section{Background}

The human brain contains approximately 100 billion neurons $[1,2]$ that are connected through trillions of synapses $[3,4]$. Thus, understanding synaptogenesisthe process by which synaptic connections develop and mature, allowing neurons to form circuits that underlie perception, cognition and behavior-remains a monumental task. Chemical synapses are, with few exceptions, specialized asymmetric junctions that link a presynaptic neuron and a postsynaptic target $[5,6]$. In humans, synaptogenesis begins primarily during embryonic

\footnotetext{
* Correspondence: seth_johnson@hms.harvard.edu;

davie_vanvactor@hms.harvard.edu

${ }^{\dagger}$ Vivian T. Chou and Seth A. Johnson contributed equally to this work. Department of Cell Biology and Program in Neuroscience, Blavatnik Institute, Harvard Medical School, Boston, MA 02115, USA
}

development [7]. Synaptogenesis follows the process of axon pathfinding, whereby a motile structures known as growth cones at the axon tip navigate through a complex and dynamic environment to make physical contact with their proper targets by responding to a series of extracellular guidance cues $[4,8,9]$. Once axons arrive at their destinations, synapse formation is initiated through various adhesive interactions via cell-adhesion molecules (CAMs), substrate-adhesion molecules (SAMs), and bi-directional signaling between the preand postsynaptic compartments [5, 7]. As the synapse matures, the presynaptic axon assembles the machinery that mediates efficient neurotransmitter release via membrane fusion of synaptic vesicles (SV). SV release is triggered by an influx of $\mathrm{Ca}^{2+}$ ions via voltage-gated

C The Author(s). 2020 Open Access This article is licensed under a Creative Commons Attribution 4.0 International License, which permits use, sharing, adaptation, distribution and reproduction in any medium or format, as long as you give appropriate credit to the original author(s) and the source, provide a link to the Creative Commons licence, and indicate if changes were made. The images or other third party material in this article are included in the article's Creative Commons licence, unless indicated otherwise in a credit line to the material. If material is not included in the article's Creative Commons licence and your intended use is not permitted by statutory regulation or exceeds the permitted use, you will need to obtain permission directly from the copyright holder. To view a copy of this licence, visit http://creativecommons.org/licenses/by/4.0/ The Creative Commons Public Domain Dedication waiver (http://creativecommons.org/publicdomain/zero/1.0/) applies to the data made available in this article, unless otherwise stated in a credit line to the data. 
channels and occurs within specialized regions known as active zones (AZ) [7, 10-14]. Concurrently, the postsynaptic compartment, which may be the dendrite of another neuron or another cell type, accumulates neurotransmitter receptors within specialized regions that form in precise alignment with the presynaptic release sites [15-17].

Although understanding the glutamatergic synapses of the vertebrate central nervous system (CNS) is arguably one of the premier goals of neuroscience, PNS synapses of worms and flies, such as at the neuromuscular junction (NMJ), are particularly suitable models because they are tractable but also bear striking structural and chemical similarity to the synapses of the vertebrate CNS. Profound insights on the excitatory glutamatergic synapse in particular have emerged from studies of the Drosophila larval NMJ (Fig. 1) [18-22]. In the fly, the NMJ is a stereotyped structure that is easily accessible through dissection but also via non-invasive imaging through the translucent larval cuticle. More broadly, the
Drosophila NMJ can be manipulated with sophisticated genetic mutagenesis, screening, expression, and editing strategies and is amenable to advanced biochemical, electrophysiological, ultrastructural, and light imaging techniques. Throughout synaptogenesis in Drosophila, conserved signaling pathways such as Bone Morphogenetic Protein (BMP) [23, 24], Wnt/Wingless (Wg) [25-27], Fibroblast Growth Factor (FGF) [28], and leukocyte common antigen-related receptor protein tyrosine phosphatase (LAR-RPTP) [29-32] coordinate the complex interplay of cellular and molecular events.

Synaptogenesis is not a singular event but rather a dynamic process. While the most intense period of synaptogenesis occurs during embryonic and early postnatal stages, nervous system development persists throughout adolescence and even into the third decade of human life [33]. Such changes encompass not only the addition of new synapses but also their "pruning" or removal; it is estimated that half of the synapses within the prefrontal cortex of human newborns are removed

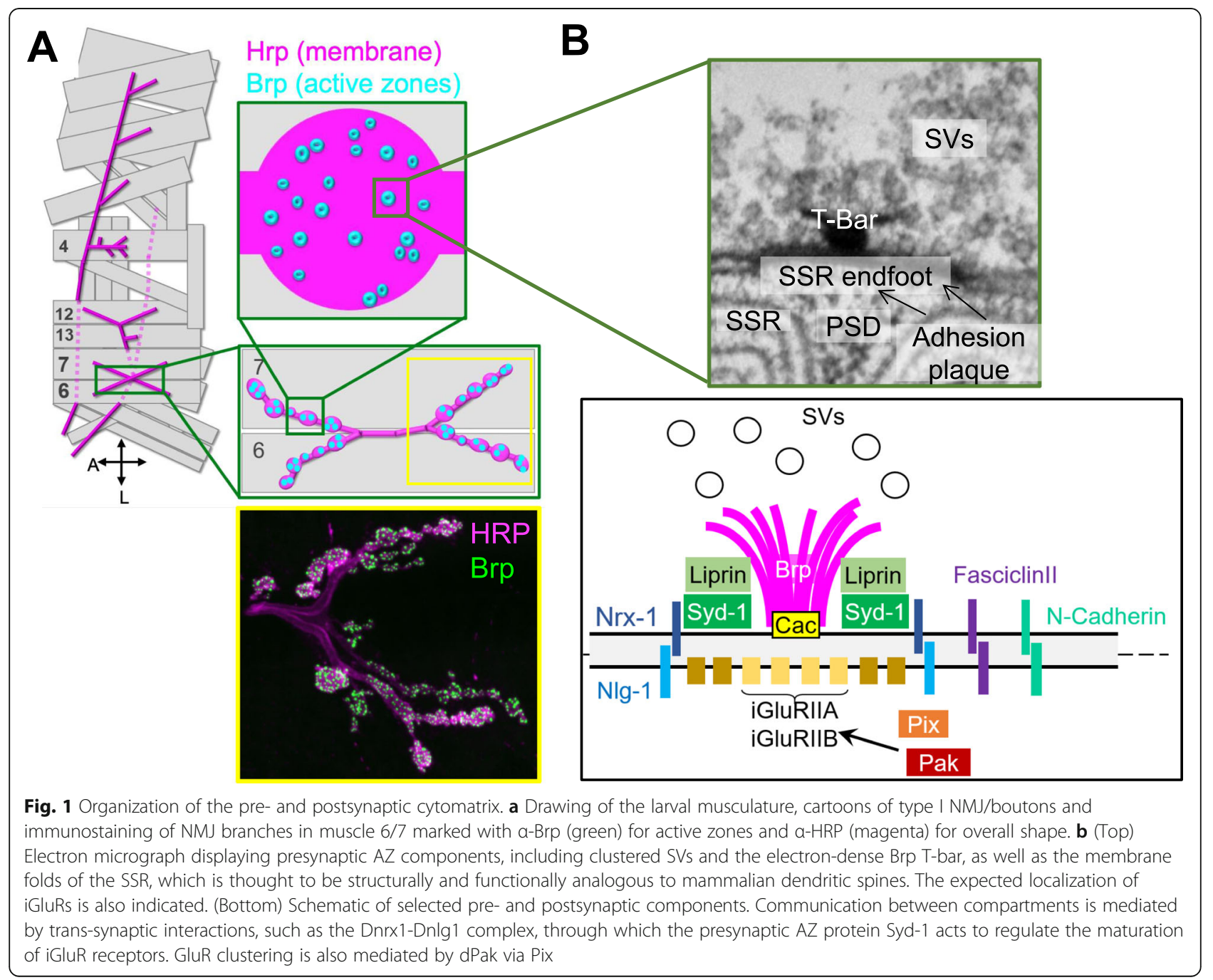


by adulthood [33]. Importantly, structural plasticity forms the basis of learning and memory and reflects the ability of synapses to respond not only to baseline developmental cues but to acute external stimuli $[6,34,35]$. This remarkable property of neurons is predicated on reciprocal bidirectional signaling and precisely orchestrated assembly and function of both the pre- and postsynaptic compartments $[6,34,35]$, emphasizing the importance of understanding the synapse as an integrated whole.

\section{Synaptic specification: finding the right target}

Upon physical contact of the axonal growth cone with its target, the specification and alignment of the correct pre- and postsynaptic partners is coordinated by various CAMs [7, 36-38]. CAMs act throughout synapse development, and beyond their roles in physical adhesion, also function as trans-synaptic signaling molecules and are involved in processes ranging from SV organization, receptor clustering, and structural and functional plasticity [36-38]. Key conserved regulators of CAM interactions include the trans-synaptic binding Eph receptor tyrosine kinases and their ligands, ephrins, which can both be expressed in either the pre- or postsynaptic compartment and facilitate bidirectional communication to regulate synaptic morphogenesis and plasticity [39, 40]. CAMs are divided into two classes: those that engage in homophilic interactions with another molecule of the same type, and those that engage in heterophilic interactions with a different CAM or to substrate adhesion molecules (SAMs) in the extracellular matrix (ECM) $[36,41]$. CAMs are not necessarily limited to a single mode of binding. For instance, SynCAM [42-44] and the type II classical cadherins [45] display both homophilic and heterophilic binding in vivo, while type I classical cadherins show both forms of binding in vitro [46, 47], although only homophilic interactions are observed in vivo [48].

Conventionally homophilic CAMs include NCAM/ CD56 $[49,50]$ and the related Drosophila protein Fasciclin II (FasII) [51-53]; DSCAM [54, 55]; SynCAM [42-44]; and the type I and II classical cadherins [56-59]. Of the homophilic CAMs, the type I cadherin Cadherin-N/Cadherin $2(\mathrm{CadN})$ is the most highly expressed as well as best studied in the context of the CNS. CadN localizes within the synaptic cleft [60] and adjacent to presynaptic AZs [61] and redistributes in response to activity [62]. Beyond providing adhesive connections, CadNs are involved in neurotransmission [63], presynaptic short-term plasticity [64], dendritic spine morphogenesis [65, 66], activity-dependent plasticity and stabilization of dendrites [67, 68], and long-term potentiation [69, 70]. Other homophilic CAMs have similarly diverse functions, including neuronal morphogenesis [71-74], homeostatic [75] and activity-dependent plasticity [50, 53], organization of synaptic architecture [42, 76], and long-term potentiation $[49,77]$.

Heterophilic interactions at the synapse are mediated by CAMs such as Neurexins and Neuroligins [78-81], Teneurins [82, 83], and Drosophila Dprs and DIPs [84, 85]. The highly conserved Neurexins and Neuroligins are perhaps the best-characterized synaptic CAMs of all. Neurexins include three vertebrate members and a single fly homolog, Neurexin-1 (Nrx-1), while vertebrate Neuroligins 1-4 each have a corresponding Drosophila homolog (Nlg1-4) [78, 80]; additional homologs of both Neurexin and Neuroligin are present across various taxa. Neurexins and Neuroligins are both exclusively synaptic, and expression of either is sufficient to induce synaptic differentiation in vitro [86, 87]. Loss of either Neurexins or Neuroligins results in severe, or even lethal, defects in synapse formation and function in multiple systems [88-92], reflecting their central role in promoting the formation of stable junctions between pre- and postsynaptic components across organisms [88, 93-98]. Work at the Drosophila NMJ indicates that the postsynaptic targets of Nrx-1-Nlg1 include neurotransmitter receptors [93] and the WAVE regulatory complex, which modulates actin cytoskeletal dynamics [99]; downstream presynaptic targets of Nrx-1-Nlg1 include core AZ components [93] and BMP pathway receptors and effectors [94]. Further evidence for the bidirectional nature of Nrx-1-Nlg1 complex-mediated interactions include the finding that the presynaptic AZ component Syd-1 binds Nrx-1 directly to act via Nrx-1-Nlg1 to regulate GluRs composition and clustering [93]; this illustrates one mechanism by which the core AZ machinery can organize their postsynaptic counterparts. Moreover, loss of muscle Nlg1 results in defects in both presynaptic morphology and AZ assembly, indicating a reciprocal mechanism by which the postsynaptic apparatus can regulate release sites [93]. Interestingly, Nlg1 also regulates BMP pathway receptor subunits Wit/Tkv and the Mad [94], in a retrograde manner, further underscoring the bidirectional nature of Nrx-1-Nlg1 function.

It is worth noting that Drosophila motor neurons also express a protein known as Neurexin IV (Nrx-IV) [100] that is more properly classified as an ortholog of the contactin-associated protein (CASPR)/paranodin/CNTN AP family of receptors implicated in human autismspectrum disorders $[101,102]$. Although structurally similar from the C-terminus through the transmemembrane peptide and membrane proximal LamG repeats, this CASPR/CNTNAP branch of the Nrx family tree has one fewer LamG domains, and two additional extracellular domains (the FIB motif and N-terminal DISC domain). Nrx-IV is best known in fly for its vital role in 
septate junctions formed between glial cells to create an impermeable barrier between the CNS and the hemolymph [103]. However, Nrx-IV also participates in glial-neuronal interactions in multiple contexts [104106]. Interestingly for this review, Nrx-IV plays an unexpected role Drosophila synapse biology, as alterations in presynaptic Nrx-IV expression levels results in abnormal NMJ morphology and AZ density synaptic morphology [107]. These functions of Nrx-IV are thought to be downstream of the micro (mi) RNA miR-34, which coordinates both pre- and postsynaptic synaptogenesis [108]. So far, it is not known whether this role for NrxIV is mediated by postsynaptic Nlg, or previously identified Nrx-IV receptor/co-receptors.

In comparison to decades of work on CAMs such as CadN and NCAM/FasII or the Neurexins and Neuroligins, recognition of the importance of Tenurins and Dprs/DIPs has been relatively recent. The highly conserved Teneurins include four vertebrate members, one C. elegans member, and two Drosophila members [82]. Vertebrate Teneurins have been best characterized for their roles in partner matching and cellular specificity in the visual system [109]. At the fly NMJ, presynaptic Ten-a and postsynaptic Ten-m form a heterophilic complex that regulates synaptic specification, neuronal morphology, synaptic architecture, and neurotransmission [110]. Notably, loss of neuronal ten-a and muscle ten- $m$ produces defects in not only their respective compartment but also in the apposing cell: ten- $a$ phenotypes include reduction in postsynaptic spectrin and the subsynaptic reticulum (SSR), while ten-m phenotypes include disruptions in presynaptic MTs, SVs, and T-bar morphology [110]. These findings demonstrate that Teneurins, along with Neurexin and Neuroligins, can mediate communication across the synaptic cleft in both anterograde and retrograde directions.

The trans-synaptic binding and downstream output of CAMs, in concert with other signaling cues and interactions with the ECM, orchestrates membrane contacts between pre- and postsynaptic partners. Expansion of the fly NMJ occurs through the Wnt/Wg- [111] and BMP-dependent $[112,113]$ addition of new boutons. Possible modes of bouton addition include asymmetric budding, similar to yeast cell division; symmetric bouton division; or de novo formation from the axon shaft [114]. Besides bouton addition, bouton elimination or pruning is also critical to refinement of synaptic structure and preventing overexuberant growth $[18,19]$. Intermediary structures such as presynaptic "debris" and filopodia-like synaptopods are also observed during synaptic expansion, although unlike boutons, such structures are only observed very transiently $[18,19,111$, 115]. These sequential morphological processes of bouton addition, followed by expansion to full size and if necessary, pruning, are modulated by baseline and/or activity-dependent signaling cues to achieve a synaptic size and structural that facilitates proper connectivity and strength.

\section{Rapid initiation of presynaptic AZ assembly}

During the morphogenesis of the larval type I bouton (both Ib and Is; refer to [116, 117] for detailed discussion of synapse and bouton types), initial outgrowth of membrane precedes recruitment of functional and architectural synaptic components. In support of this, numerous light imaging experiments in Drosophila have revealed that nascent boutons initially lack pre- and postsynaptic specializations $[111,118,119]$. Subsequent correlated timelapse light and ultrastructural studies in flies have shown that these immature "ghost" boutons are highly transient, as AZ precursors and SV docking become visible within minutes. Postsynaptic specializations are slower to form however with some components taking hours to arrive and fully accumulate $[120,121]$. These processes of bouton addition and maturation can still be observed in cut axons, albeit at a lower frequency than in intact preparations, indicating local machinery is sufficient to support at least some level of synaptic expansion in the absence of protein synthesis [119].

The accumulation of AZ components produces a dense matrix of proteins, of which at least five are extensively conserved across multiple taxa: RIM/Unc-10, Munc13/Unc13, RIM-Binding Protein (RBP), Liprin- $\alpha /$ SYD-2, and ELKS/CAST/ERC/Bruchpilot (Brp) [11, 12]. Recent data suggests that while the AZ protein Syd-1 was formerly thought to be exclusive to invertebrates [122-124], new findings reveal a mouse homolog called MSYD1A [125]. However, when these components are viewed with ultrastructural resolution, the morphology varies across synapses and organisms (reviewed [11, 13]. For instance, Drosophila NMJs display a T-bar structure at the center of a larger an adhesion plaque characterized by electron-dense membrane morphology and a ladder-like set of repeated membrane-membrane crossbridges (Fig. 1). In vertebrates, a grid-like arrangement of pyramidal dense projections have been described at the CNS [126], and sensory synapses display "ribbon" projections [127], which can range from flattened to spherical structures [128]. Notwithstanding these morphological variations, the accumulated evidence suggests that these dense projections have fundamentally similar roles in the function and organization of the presynapse; among these roles is the physical tethering of SVs via filaments to these projections, as has been observed in mice [129], frogs [130], and flies [131].

Despite the existence of local assembly mechanisms within the axonal compartment [119], in general, AZ development relies on trafficking of $\mathrm{AZ}$ components, as 
well as SV precursors (SVPs) and other materials, via long-range motor transport from the cell body [132136], although mechanisms such as diffusion may also contribute [137, 138]. Several models exist for how AZ and SV components are organized into functional structures at release sites. Ex vivo studies have suggested the possibility that specialized dense core vesicles (DCVs) known as Piccolo/Bassoon Transport Vesicles (PTVs) traffic components in a unitary/quantal manner, such that each PTV contains a pre-assembled AZ "packet" $[139,140]$. It has been proposed that AZ and SV materials are co-transported in aggregates of 1-2 PTVs and 5-6 SVPs that can very quickly form a functional AZ upon delivery [141-145]. However, the existence of PTVs and ready-to-go AZs packets has not been conclusively established through in vivo studies $[146,147]$, and to date, there is no evidence for PTVs containing preassembled AZs at the Drosophila NMJ or other invertebrate synapses, although interestingly, lysosome-related vesicles (PLVs) have been found to transport SVs and AZs in the Drosophila motor neuron axon [148].

\section{Early AZ assembly: SYD-1, LIPRIN-A, and UNC-13}

In contrast to the above model of pre-assembled AZs, in vivo studies in invertebrates suggest that while AZ assembly occurs very rapidly, a sequence of steps can still be distinguished (Fig. 2c) [146]. In support of hierarchical AZ assembly, ample studies in C. elegans and Drosophila indicate that two of the earliest components to be recruited to presynaptic AZs are the scaffolding proteins Syd-1/SYD-1 and Liprin- $\alpha /$ SYD-2 (synapse-defective) [93, 122-124, 149-154]; evidence in flies suggests that these components may precede other AZ proteins by hours [122, 149]. In both worms and flies, Syd-1 and Liprin- $\alpha$ have close spatial as well as functional relationships in driving early AZ assembly [122, 124] as well as SV organization [152, 154]. In flies, loss of syd-1 and liprin- $\alpha$ results in reduced NMJ size as well as increased $\mathrm{AZ}$ size as observed by light and electron microscopy, respectively $[120,122]$, indicating potential defects in AZ organization. Furthermore, loss of either syd-1 or liprin$\alpha$ in Drosophila leads to decreased neurotransmission $[120,122]$.

The Syd-1 scaffold protein localizes to punctate clusters in presynaptic terminals and appears to be nervoussystem specific in worms $[123,124,155]$, as well as in flies [122]. Early studies established that Syd-1 has PDZ, $\mathrm{C} 2$ and RhoGTPase-activating protein (GAP)-like domains [155], although the RhoGAP activity of Syd-1 was long disputed and was only recently discovered to be required for the clustering of ELKS/Brp [153]. Syd-1 is potentially one of the earliest $\mathrm{AZ}$ components to be concentrated at the nascent AZ, as Syd-1 is upstream of Liprin- $\alpha$ in C. elegans $[123,124]$ as well as in Drosophila, where Syd- 1 is required for proper Liprin- $\alpha$ accumulation [122]. Syd-1 also interacts with the Nrx-1-Nlg trans-synaptic adhesion complex via direct binding to Nrx-1 to regulate postsynaptic receptor clustering [93]. To date, no unambiguous mammalian homologs of Syd1 have been identified, although mouse MSYD1A has been suggested as a possible homolog on the basis of partial sequence similarity and comparable roles in SV docking and synaptic transmission [125].

In contrast to Syd-1, the Liprin family member Liprin$\alpha$ is highly conserved across metazoans, with $\sim 50 \%$ similarity between the human and C. elegans homologs, and is widely expressed in many tissues in addition to the nervous system $[121,156]$. Liprin- $\alpha$ has been wellcharacterized in the presynaptic compartment, and interestingly, has also been found to have a highly abundant postsynaptic expression, likely indicating postsynaptic roles $[121,156]$. Structurally, Liprin- $\alpha$ contains an $\mathrm{N}$-terminal coiled-coil region that mediates homo- and hetero-multimerization and an C-terminal Liprin homology $(\mathrm{LH})$ region containing three SAM (sterile- $\alpha$-motif) domains $[120,157,158]$. The SAM domains of the LH region, in particular, are thought to mediate the interactions of Liprin- $\alpha$ with Syd- 1 and at least a dozen other proteins involved in synaptic development and/or function [121, 156]. Indeed, Liprin- $\alpha$ was first identified from its interactions with a member of the LAR-RPTPs, including vertebrate LAR, PTP $\delta$, and РТРб [157, 158]; while these initial observations were at the focal adhesions of non-neuronal cells, studies of LAR as well as Liprin- $\alpha$ have since focused on their diverse functions in the nervous system. LAR, in particular, has critical roles in axon guidance, neurite extension, as well as synapse assembly, formation, and plasticity $[29,30]$. The Liprin family proteins also include Liprin- $\beta$, which, like Liprin- $\alpha$, is required to promote synaptic expansion at the fly NMJ, and Liprin$\gamma /$ KazrinE, which antagonizes the function of Liprin- $\beta$ at the NMJ [151]. However, the roles of Liprin- $\beta$ and Liprin- $\gamma$ remain largely unknown in comparison to Liprin- $\alpha$, and it remains to be seen whether they have roles at the AZ.

A recent study in Drosophila has shown that Unc13A, one of the two fly isoforms of Unc13, a central regulator of neurotransmitter release, may be co-recruited with Syd-1 and Liprin- $\alpha$ [103]. Unc13 was first identified in C. elegans [104], with subsequent studies demonstrating its role in SV docking, priming, and fusion [159, 160]. Unc13 primes the SNARE/SM machinery for exocytosis $[105,161]$ and regulates the kinetics of release [103]. Through its regulation of SV release, Unc13 is also involved in diverse forms of plasticity, including shortterm augmentation and long-term potentiation and depression [106, 162]. Super-resolution microscopy has 


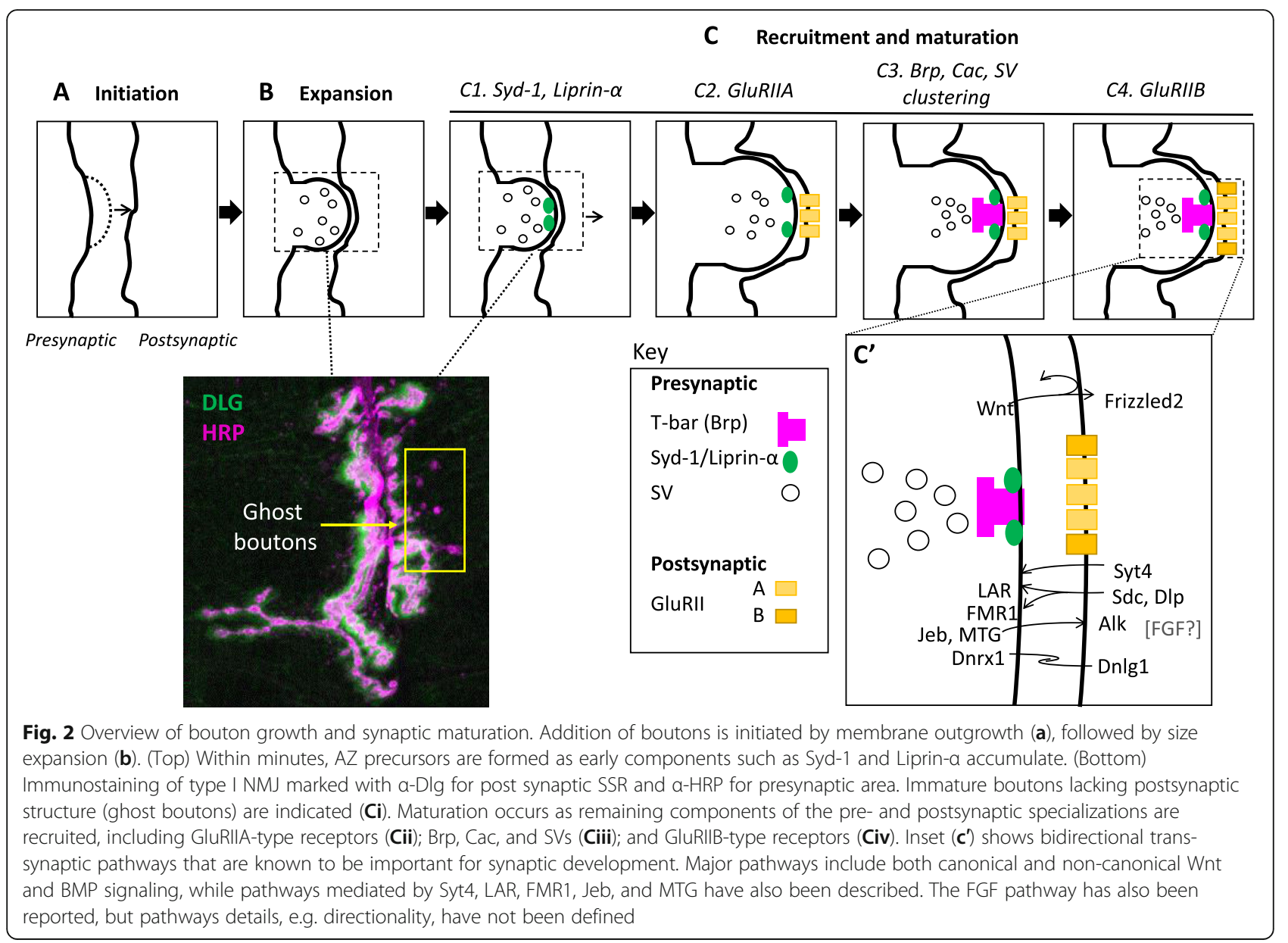

revealed that the two Drosophila isoforms, Unc13A and Unc13B, occupy distinct localization patterns relative to other core $\mathrm{AZ}$ components and to $\mathrm{Ca}^{2+}$ channels, suggesting that different isoforms may act via independent pathways to tune and optimize SV release [103]. Interestingly, the shift from recruitment of Unc13A to Unc13B that occurs as AZ assembly and maturation progresses is reminiscent of a model where distinct receptor subunits in the postsynaptic compartment are recruited in a sequential manner (see the section "The Postsynaptic Cytomatrix" for more detail on this process; Figure 2Cii-iv) [93], perhaps reflecting separate roles of individual molecular isoforms at various stages of synapse maturation.

\section{Downstream AZ assembly: rim, rim-BP, and BRP}

Following recruitment of Syd-1 and Liprin- $\alpha$ [122-124, 149], and the Unc13A isoform [103], the remaining AZ components are localized, including Unc13B, RIM/Unc10, RIM-BP, and ELKS/Brp. Like Unc-13, RIM (Rab3- interacting molecule) was first discovered as a regulator of SV release and neurotransmission [163, 164], and was later found to promote SV priming by monomerizing Unc-13 from autoinhibitory homodimeric complexes [165-167]. RIM also has roles in both short- and longterm plasticity $[168,169]$ and $\mathrm{Ca}^{2+}$ channel localization to the AZ [167, 170-172]. In particular, the regulation of $\mathrm{Ca}^{2+}$ channels by RIM is mediated by its interactions with RIM-BP [173, 174]. Together, RIM and the RIMBP scaffold protein form a complex that interact with $\mathrm{Ca}^{2+}$ channels $[172,175]$. The importance of RIM-BPs has been further demonstrated in Drosophila, where mutations in rim-bp results in defects in $\mathrm{Ca}^{2+}$ channel clustering as well as disruptions in Brp distribution, AZ ultrastructure, and synaptic release [176].

In addition to Unc-13, RIM, and RIM-BP, accumulation of the scaffold ELKS/Brp also follows initiation of AZ assembly by Syd-1 and Liprin- $\alpha$, in a process that can begin within minutes of new bouton formation [119] but that can take hours to reach completion [149]. Work in Drosophila has provided compelling clues to 
the functions of Brp at the AZ. Drosophila Brp is expressed in two isoforms, both of which are necessary at the synapse [177]. Immunofluorescence has revealed that Brp forms distinct puncta in the presynaptic terminal of the motor neuron $[178,179]$ as well as in other neurons, such as R8 photoreceptors [180]. In live fluorescent studies, a nonfunctional truncated Brp-short construct $[149,181]$ has been frequently used as a marker of the presynaptic AZ, in lieu of the full-length Brp which can aggregate upon overexpression [179]. Importantly, Brp is an essential structural component of the $\mathrm{AZ}$ and is thought to be the major component of the electron-dense T-bar visible by electron microscopy (Fig. 3) [149], with loss of Brp resulting in the complete elimination of T-bars $[178,179]$. Super-resolution stimulated emission depletion (STED) microscopy has revealed that Brp puncta are in fact donut-shaped structures that represent the top half of a funnel-shaped Brp complex which is attached to the membrane of synaptic release sites [149, 178], and that the two Drosophila Brp isoforms alternate in a circular pattern [177]. Further work combining direct stochastic optical reconstruction microscopy (dSTORM) super-resolution with electrophysiology demonstrated that mature AZs consist of approximately 137 rod-like Brp proteins organized into about 15 heptameric structures, and that proper neurotransmission relies on a precise maintenance of the stoichiometry and organization of this multimeric structure [182]. In addition to its role as a key AZ structural component, Brp is thought to regulate synaptic release by controlling the size of the readily releasable pool (RRP) of SVs [177]. Brp is also necessary for short-term plasticity and $\mathrm{Ca}^{2+}$ channel clustering [178], consistent with observations that the Drosophila $\mathrm{Ca}^{2+}$ channel subunit Cacophony (Cac) is recruited to the AZ contemporaneously [149].

The discussion in this review of AZ composition, architecture, and function addresses only a modest fraction of the expansive body of work on this highly complex and vital structure. The cytomatrix of the presynaptic AZ encompasses many other proteins, including: the scaffolds Piccolo/Fife and Bassoon; the Ras superfamily GTPases, such as Rab3 and Rac1, and their respective GAPs and guanine nucleotide exchange factors (GEFs); membrane trafficking machinery such as the SNARE proteins, synapsin, and synaptotagmin; the tripartite Cask/Mint1/Veli complex; developmental signaling pathways; and the cytoskeletal network [11, 12, 183-185]. Furthermore, despite significant progress in the field as a whole, many questions about the AZ remain. Ongoing and future studies will address topics such as the precise ultrastructure/nanostructure of the AZ, how the AZ is involved in both short- and long-term plasticity, and how the AZ senses and regulates synapse stability and integrity $[11,12]$.

\section{The postsynaptic CYTOMATRIX}

In contrast to the presynaptic terminal, which is always neuronal [7], the postsynaptic target cell is most commonly neuronal but can also be of another cell type, such as glia [186-190] or effector organs, as in the case of the Drosophila NMJ. Early ultrastructural studies of dendritic spines of mammalian excitatory synapses detected a 3-dimensional intracellular structure known as the postsynaptic density (PSD) directly underneath the spine membrane [191-193]. The dendritic spine PSD, and analogous cytomatrix structures in other postsynaptic cell types [13], is rich in diverse protein types, including neurotransmitter receptors as well as scaffolding, signaling, and cytoskeletal molecules [15-17]. Glutamate receptors (GluR), the most prevalent receptor type, are present at excitatory glutamatergic synapses that predominate in the vertebrate CNS as well as the invertebrate NMJ [194, 195]. GluRs include ionotropic GluRs (iGluRs), an abundant subtype in which the receptors themselves form an ion channel pore to mediate fast synaptic transmission on millisecond timescales; this is in contrast to metabotropic GluRs (mGluRs), which activate ion channels via secondary messengers and are moreover slower-acting and less frequently occurring [194, 195]. iGluRs can be further subdivided into AMPA-, NMDA-, and kainate-type receptors, with AMPA and NMDA receptors being most common [194]. At the Drosophila NMJ, only AMPA/kainate receptors have been identified on the basis of genomic sequencing $[195,196]$. However, more recent work has suggested that the iGluRs at the fly NMJ may be distinct from the classical vertebrate iGluR subtypes, as they display divergent structural and neurotransmitter-binding properties [197].

At the Drosophila NMJ, iGluRs are heterometric tetramers composed of three invariant subunits, GluRIII/ GluRIIC, GIURIID, and GluRIIE, as well as one of either GluRIIA or GluRIIB [198-203]. Recruitment of iGluRs to the postsynaptic cytomatrix requires the function of the essential conserved auxiliary subunit Neto [204-208] and is thought to occur after the arrival of the presynaptic AZ components Syd- 1 and Liprin- $\alpha$ but prior to the recruitment of Brp and Cac (Fig. 2c) [149]. GluRIIA and GluRIIB differ in their single channel properties, and they are responsible for large and small glutamate-gated currents, respectively [203, 209]. At the fly NMJ, proper iGluR subunit composition and GluRIIA/GluRIIB balance is regulated by Neto, likely via the recruitment of Pak [206], the Drosophila homolog of the p21activated kinase (PAK) [210, 211]. The ratio of iGluRs containing the GluRIIA versus GluRIIB subunits is furthermore regulated by the presynaptic AZ protein Syd-1 via interactions with the Nrx-1-Nlg1 complex [93] and by a non-canonical, Smad-dependent BMP pathway 


\section{A BMP Canonical Signaling}

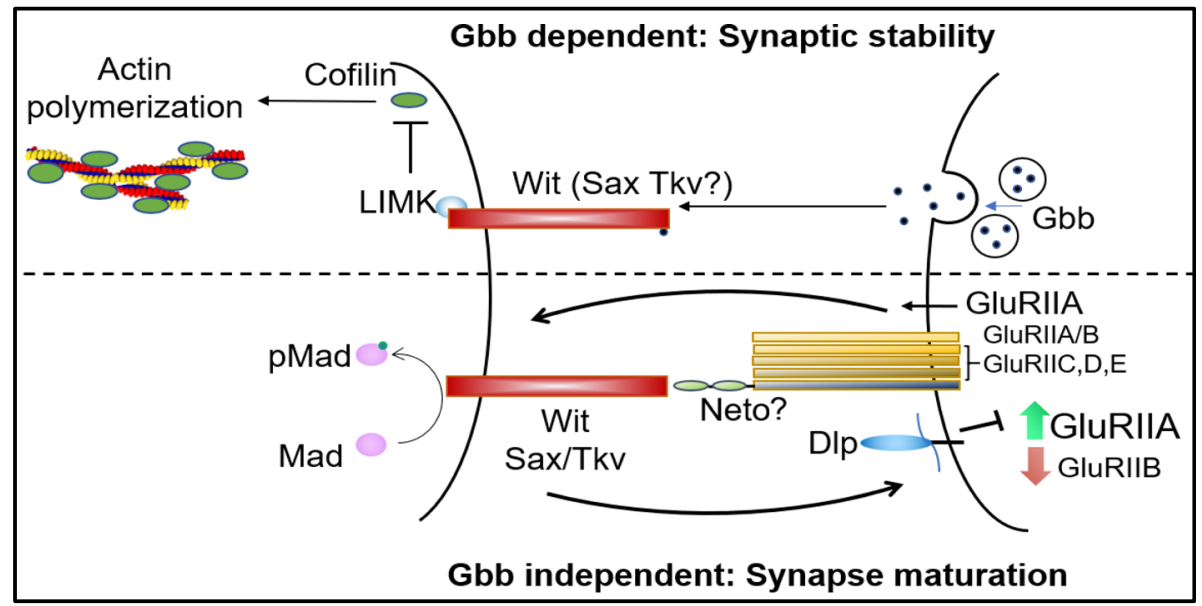

\section{B BMP Non-canonical Signaling}

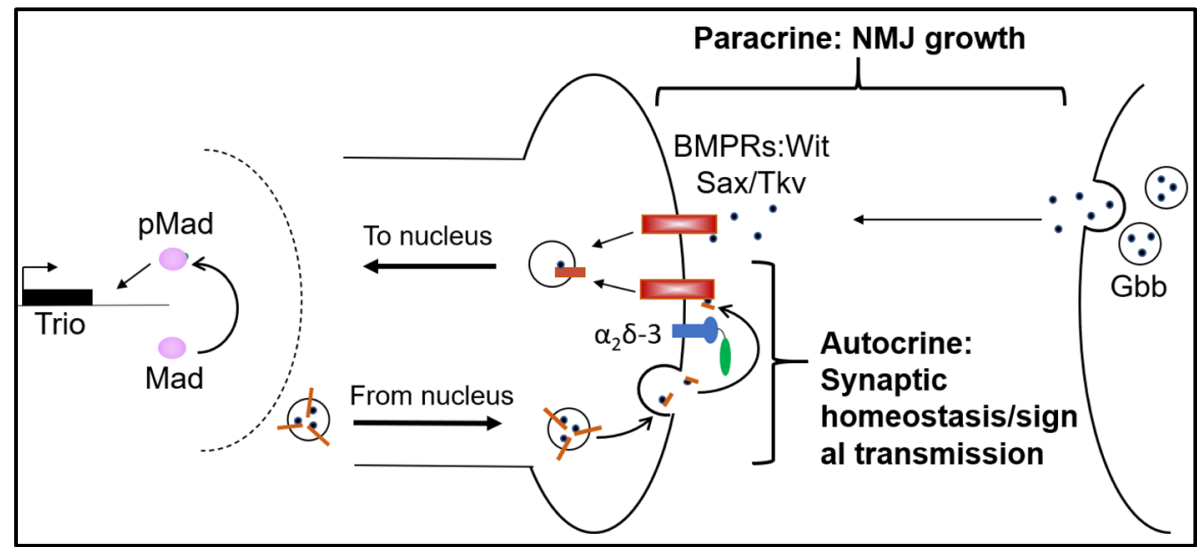

Fig. 3 BMP Canonical and Non-Canonical signaling at the NMJ. a BMP canonical signaling includes a paracrine, retrograde mechanism whereby muscle-derived Gbb is released across the synapse where it activates BMPRs Wit and Sax/Tkv triggering internalization. Internalized Gbb is trafficked to the neuronal nucleus where it activates phosphorylation of the Mad to pMad to activate transcription of Trio-GEF promoting overall NMJ growth. A second autocrine canonical pathway involves release of Cmpy bound Gbb from the neuron where it sequestered by $a_{2} \delta-3$, a calcium channel subunit. Neuronally derived Gbb then binds BMPRs and causes transcriptional changes similar to the paracrine canonical pathway to regulate synaptic homeostasis and signal transmission. $\mathbf{b}$ BMP non-canonical signaling pathways include those that are Gbb dependent and independent. Gbb dependent non-canonical signaling involves retrograde release of Gbb where it is bound by Wit. LIMK acts as a Wit effector to inhibit Cofilin which normally promotes actin dynamics through filament severing. In a Gbb independent non-canonical mechanism, GluRIIA containing iGluRs form a positive feedback loop with local presynaptic pMad. This mechanism depends on Wit and Sax/Tkv, but not on transcription and is inhibited by Dlp (Glypican)

[212]. This ratio of GluRIIA versus GluRIIB subunits changes throughout the lifespan of a synapse, with younger synapses preferentially incorporating GluRIIA, followed by GluRIIB incorporation as the synapse matures [181]. GluRIIA recruitment is thought to be an essential driver of synapse formation and its incorporation into the GluR tetramer is nearly irreversible [181, 209, 213]; this latter property, along with the tendency for GluRIIA incorporation to precede GluRIIB, likely accounts for the concentric arrangement of GluRs, where GluRIIB-rich receptors form a ring around GluRIIA-rich core (Fig. 2c) [93]. The proper temporal sequence of subunit recruitment, as well as relative spatial arrangement of GluRIIA- and GluRIIB-associated receptors is thought to be necessary not just for the initiation synaptogenesis but also subsequent stabilization and maturation [93].

Aside from neurotransmitter receptors, the postsynaptic cytomatrix is highly abundant in additional factors that play further roles in synaptic maturation and stabilization. Besides its above-mentioned roles in iGluR composition, Pak also modulates levels of the postsynaptic scaffold Discs Large (Dlg), muscle ultrastructure, and the formation of the SSR, a postsynaptic system of 
tubular-lamellar membrane folds that envelops the presynaptic bouton [214-217] that has been described as the structural and functional equivalent of dendritic spines at the Drosophila NMJ [218]. Another notable regulator of SSR expansion is Syndapin (Synd), a member of the F-BAR family of membrane-sculpting proteins $[219,220]$ that appears to exclusively postsynaptic where it likely mediates SSR development by regulating the muscle actin cytoskeleton [221, 222]. Development of the SSR also requires additional actinregulatory proteins concentrated in the postsynaptic cytomatrix, including hu-li tai shao (Hts)/Adducin, an actin-capping protein [223-225], and Enabled (Ena) [226], which promotes the assembly of linear F-actin; other key cytoskeletal regulators of SSR morphogenesis include both pre- and postsynaptic Spectrin [227, 228] and presynaptic Ankyrin [229, 230]. Finally, Dlg, a PDZ domain containing protein, vertebrate PSD-95/SAP90, belongs to the membrane-associated guanylyl kinases (MAGUKs) family of PDZ proteins $[15,16]$ and promotes the clustering of Shaker $\mathrm{K}^{+}$ion channels [231] and of FasII [232]. Dlg is also necessary for clustering of GluRIIB-containing receptors [233], while vertebrate PSD-95 regulates the clustering of NMDA receptors [234]. While Dlg is most abundant in the postsynaptic SSR, it is also present at lower levels in the presynaptic AZ [235], similar to the distribution of Liprin- $\alpha[121,156]$.

Some factors traditionally associated with chiefly pre or postsynaptic roles including Dlg and Liprin- $\alpha$, also display opposite localization albeit at a reduced abundance, suggesting the need to reconsider these factors for in new contexts. Dlg presents a presynaptic pool similar to Liprin- $\alpha$ which has been shown to promote the AZ localization of $\mathrm{Cac}$, with effects on synaptic release probability and short-term plasticity [236]. Liprin- $\alpha$, which has been chiefly studied as a presynaptic AZ protein, displays an overwhelmingly postsynaptic distribution [121, 156]. Postsynaptic Liprin- $\alpha$ interacts with the PDZ-domain protein GRIP in the PSD and is also regulated by the $\mathrm{Ca}^{2+} /$ calmodulin- dependent protein kinase II (CaMKII) [237]. Outside of these studies, the roles of postsynaptic Liprin- $\alpha$, including at the Drosophila NMJ, is largely a mystery, and may prove fertile ground for future inquiry. It is also interesting to consider the possible postsynaptic expression of other conventionally presynaptic proteins, such as Syd-1, which appears to display some postsynaptic staining [122].

\section{Trans-synaptic communication between compartments}

Despite distinctions between pre- and postsynaptic compartments, effective bidirectional communication is essential to the coordinated assembly, maturation, and function of the entire synapse (Fig. 2c'). Key orchestrators of trans-synaptic communication include signal transduction pathways, including the Wnt/Wg pathway as a primary driver of anterograde signaling [25-27], and the BMP pathway as a major contributor to retrograde signaling [24]. These signaling pathways control many different aspects of neurodevelopment including growth, signal transmission, synaptic maturity, AZ assembly and homeostasis. Intriguingly, these many functions are controlled by signaling pathways that share many similar growth and downstream factors yet are capable of distinguishing between these functions as required during development. This section will detail the different categories and subcategories of signaling and describe how the developing NMJ is capable of discriminating between them.

At the fly NMJ, Wg participates in both anterograde and autocrine signaling. $\mathrm{Wg}$ is secreted from the presynaptic terminal and binds Frizzled2 (Fz2) receptor embedded in the postsynaptic membrane. Activation of Fz2 triggers internalization and cleavage of the receptor allowing a C-terminal fragment (Fz2-C) to enter the postsynaptic nucleus where it contributes to changes in gene expression thereby positively regulating synaptic expansion and plasticity [27, 238]. Retrograde Wg signaling is negatively modulated by several extracellular factors including extracellular matrix metalloproteinase enzymes (MMPs) and the decarboxylesterase Notum, which cleave HSPG co-receptors and Wg, respectively to limit signaling [239]. Presynaptic Wg ligand also mediates a divergent canonical pathway that regulates the presynaptic cytoskeleton. Neuronally derived Wg inactivates glycogen synthase kinase 3 (GSK3)/Shaggy, which in turn regulates microtubule dynamics through interactions with the Map 1B homolog Futsch [240-242].

BMP signaling controls many aspects of neuronal development at the NMJ including growth, synaptic transmission and synaptic homeostasis. Many of these functions of BMP signaling do not happen concurrently, yet use many the same factors to elicit these responses. How then do cells disentangle each of these signaling functions to achieve proper development? Recent exciting findings complement past studies to show how we can begin to separate these functions in terms of differences in signaling. Drosophila utilize both canonical and non-canonical BMP signaling. In the canonical BMP pathways, the Glass Bottom Boat (Gbb) ligand, most homologous to BMP7, is secreted by the muscle and binds with tetrameric complexes containing the type II receptor Wishful Thinking (Wit) and the type I receptors Thickveins (Tkv) and Saxophone (Sax). This interaction mediates the phosphorylation of the transcription factor Smad/Mothers against decapentaplegic 
(Mad) [243-245], which affect transcription leading to activity-dependent growth or synaptic clustering [113]. Canonical BMP signaling may also regulate actin through its interactions with the Rho-GEF Trio; it is thought that the retrograde BMP pathway regulates transcription levels of presynaptic Trio to restrict synaptic growth [246].

While the previous canonical BMP description represents an anterograde, transsynaptic mechanism, a second canonical BMP pathway involves an autocrine signaling mechanism where an activity-dependent stimulus directs synaptic strengthening and maturation [247]. Autocrine signaling occurs when an activity dependent stimulus promotes release and reabsorption of Gbb by the motorneuron, triggering a locally sustained BMP response. Recently, a calcium channel subunit $\left(\alpha_{2} \delta-3\right)$ was found to physically interact with neuronally-derived Gbb and was required to limit the range at which Gbb could work to strengthen the synapse [248].

Both paracrine and autocrine BMP canonical signaling utilize Gbb binding to Wit to cause a signaling cascade allowing pMAD to regulate transcription. How then does the motor neuron distinguish between these two signals to regulate two separable functions (bouton growth and synaptic (AZ) density)? Temporal requirements for each type signal partially explain the separability as the muscle-derived growth signal is primarily needed early phases (L1), while the sustained neuronally derived signal is required at later stages to refine and strengthen the synapse [248]. Additionally, factors that interact with Gbb can also separate functions. Crimpy (Cmpy) physically interacts with Gbb to promote recruitment of Gbb to dense core vesicles (DCVs) where it can be released from neuronal terminals with the Cmpy ectodomain [249]. Loss of Cmpy causes excessive growth, likely because without Cmpy, the neuron misinterprets autocrine BMP signaling for muscle-derived BMP signaling, which normally controls overall growth.

Several non-canonical BMP pathways have also been identified and be divided based upon whether they utilize Gbb. Non-canonical Gbb-dependent signaling controls bouton growth and occurs when, Gbb is secreted by the muscle and interacts with neuronal Wit to activate LIM Kinase1 (LIMK1). LIMK1 regulates activity-dependent bouton formation by promoting actin polymerization [112, 250]. Non-canonical Gbb-indepen dent signaling promotes stability of GluRIIA subunits in the glutamate receptor heterotetramer. Gbb-independent non-canonical signaling involves a positive feedback loop whereby GluRIIA promotes accumulation of a local presynaptic pool of pMad at the AZ. pMad in turn serves to cluster and stabilize additional GluRIIA subunits preferentially over GluRIIB [212]. Importantly, this instance of BMP signaling utilizes a separate pathway from the canonical BMP signaling as the accumulation of synaptic pMad does not lead to NMJ overgrowth seen when nuclear pMad acts as a transcriptional regulator. Furthermore, while this positive feedback mechanism does require Wit and Sax, it does not utilize LimK, distinguishing it from non-canonical Gbb-dependent BMP signaling. If this pathway does not communicate through a diffusible factor like Gbb, how then is transsynaptic communication achieved? As pointed out in Sulkowski et al., the synaptic cleft is $\sim 200 \mathrm{~A}$ and GluR tetramer and BMP receptors (BMPRs) extend $\sim 135 \mathrm{~A}$ and $\sim 55 \mathrm{~A}$, respectively into the synaptic cleft space. The GluR auxiliary protein Neto increases the span of the GluR tetramer suggesting it could serve as the transsynaptic link, though careful testing of this model is needed.

Besides Wnt/Wg and BMP, numerous other signal transduction pathways of consequence have been described at the fly NMJ. Multiple studies have established roles of retrograde signaling by Synaptotagmin 4 (Syt4) $[251,252]$ and LAR (Leukocyte common antigen related) [31, 120]. While Syt1, the other synaptically-expressed Drosophila synaptotagmin isoform, is associated with presynaptic SVs [253], Syt4 is a strictly postsynaptic $\mathrm{Ca}^{2+}$ sensor that regulates presynaptic SV fusion and activity-dependent structural plasticity in response to postsynaptic $\mathrm{Ca}^{2+}$ influx [251, 252]. Synaptic signaling is also regulated by heparan sulfate proteoglycans (HSPGs) such as Dallylike (Dlp) and Syndecan (Sdc), which impact multiple pathways including Wnt/Wg and BMP $[254,255]$. Dlp acts as a negative brake on the positive feedback loop between GluRIIA and presynaptic pMad that is itself inhibited by presence of Octopamine, the Drosophila analog of nonadrenaline [256]. Additionally, Dlp and Sdc regulate the RPTP LAR, with effects on presynaptic neuronal morphology and AZ assembly [31, 120]. An open question is whether the interaction of these HSPGs with LAR results from a direct physical binding, or whether it involves another mechanism, such as secretion of a factor. Moreover, the effect of HSPGs on both LAR and BMP signaling, along with the observation that the Rho-GEF Trio is downstream of both LAR [257, 258] and BMP [246], raises the possibility of cross-talk between the two pathways. Dlp and Sdc have more recently been found to also act via the intracellular Fragile X Mental Retardation 1 (FMR1) protein in a retrograde manner in order to interface with the Wnt and Jelly Belly-Anaplastic Lymphoma Kinase (Jeb-Alk) signaling pathways [259]. The Jeb-Alk pathway is itself an anterograde trans-synaptic signaling pathways that regulates presynaptic morphology and neurotransmission [260] under the control of Mind-TheGap (MTG), a presynaptically secreted molecule that modulates the extracellular environment of the synaptic cleft [19, 261-263]. 
Interestingly, the two Drosophila FGF receptors, Heartless ( $\mathrm{Htl}$ ) and Breathless (Btl), have been reported to interact with the spinal muscular atrophy-associated (SMA) protein Survival Motor Neuron (SMN) to regulates NMJ morphogenesis, consistent with the roles of FGF at vertebrate synapses [28, 264, 265]. Muscleexpressed Htl is itself required for presynaptic morphology, although the precise trans-synaptic mechanisms by which this is achieved remain to be defined [28]; nonetheless, observation that both SMN [266] and Htl [28] co-localize with the postsynaptic SSR raises the possibility that SMN functions downstream of FGF signaling in muscle. This interaction is intriguing given that SMN also appears to function downstream of the presynaptic BMP effectors Mad and Dad [266], suggesting that synaptic SMN may respond to distinct inputs in presynaptic and postsynaptic compartments. Indeed, SMN is known to be required on both sides of the synapse to support normal NMJ development and growth [28, 266-268] a property of multiple molecules that shape NMJ structure and function [226, 235, 269-272].

Many of the molecules and pathways involved in the communication mechanisms described above have wellestablished roles in regulating both bouton morphogenesis and AZ assembly, raising the possibility that these two processes are coupled. In fact, the morphological and $\mathrm{AZ}$ phenotypes associated with numerous $\mathrm{Wg}$, BMP, and LAR pathway components are consistent with an inverse relationship between the assembly of the AZ and the size of presynaptic terminals as determined by bouton number. For instance, within the LAR pathway, this correlation is true for the LAR receptor itself as well as for Liprin- $\alpha$ [120], the HSPG ligand Dlp [273], the kinase Abelson (Abl) [274], the Rho-GEF Trio [153, 275], and the F-actin assembly molecule Ena [269]. The negative correlation between AZ and NMJ size is also observed for Syd-1, and its downstream effectors Nrx-1 and Nlg1; while Syd1 and Nrx-1-Nlg are not confirmed LAR interactors, they potentially interface with the LAR pathway through the interaction of Syd-1 and Liprin- $\alpha$ [93, 122]. While causative relationships and underlying mechanisms cannot yet be concluded, the accumulated evidence suggests that the regulatory machinery of bouton growth and AZ assembly are not independent. The coordination of morphogenesis and $A Z$ formation may ensure the proper allocation of a finite pool of biological material; this is consistent with the finding that stoichiometric and homeostatic remodeling of the AZ dynamically tunes synaptic strength [276]. Thus, a conceivable explanation for coordination of these processes is that restricting $\mathrm{AZ}$ size ensures that all boutons are populated with release sites even as membrane expansion continues.

\section{Conclusions}

At present, the homologs of $75 \%$ of all human disease genes have been discovered in Drosophila at nearly 600 loci, further underscoring the relevance of flies to human biology [277, 278]. This suggests that Drosophila can continue to be an excellent model for studying molecules and processes with close analogs at the human synapse while using tools and methods that may not be as readily available or effective in higher organisms. It can be expected that key insights on synaptic biology and connectivity will continue to emerge from studies of the larval NMJ, as well as additional synaptic contexts, such as the adult fly visual system and the NMJs of fly embryos and earlier-stage larva. The potential of model systems such as Drosophila, combined with everaccelerating innovations in experimental and analytical techniques, presages exciting steps forward in tackling the fundamental questions of modern neurobiology.

\section{Abbreviations}

Abl: Abelson; Alk: Anaplastic Lymphoma Kinase; AMPA: a-amino-3-hydroxy-5methyl-4-isoxazolepropionic acid; AZ: Active zone; BMP: Bone Morphogenetic Protein; Brp: Bruchpilot; Btl: Breathless; Cac: Cacophony; CAM: Cell-adhesion molecule; CaMKII: Ca2+/calmodulin-dependent protein kinase II; CASP R: Contactin-associated protein; CAST: Cytomatrix at the active zoneassociated structural protein; CNS: Central nervous system; Dad: Daughters against decapentaplegic; DCV: Dense core vesicle; DIP: Dpr Interacting Protein; DLG: Discs LargeDlpDallylike protein; Dpr: Defective Proboscis Extension Response; Nlg: Drosophila Neuroligin; Nrx-1: Drosophila Neurexin; DSCAM: Down Syndrome Cell-Adhesion Molecule; dSTORM: Direct stochastic optical reconstruction microscopy; ELKS: Protein rich in the amino acids $E, L$, K and S; Ena: Enabled; ECM: Extracellular matrix; ERC: ELKS/RAB6-interacting/ CAST family member; FGF: Fibroblast Growth Factor; FMR1: Fragile X Mental Retardation 1 protein; GABA: Gamma aminobutyric acid; GAP: GTPaseactivating protein; Gbb: Glass Bottom Boat; GEF: Guanine nucleotide exchange factor; GluR: Glutamate receptors; GSK3: Glycogen synthase kinase 3; HSPG: Heparan sulfate proteoglycan; Htl: Heartless; Hts: Hu-li tai shao; iGluR: Ionotropic GluR; Jeb: Jelly Belly; LAR: Leukocyte common antigenrelated; LIMK1: LIM Kinase1; Liprin: LAR-interacting protein; LH: Liprin homology; Mad: Mothers against decapentaplegic; MAGUK: Membraneassociated guanylyl kinases; Mav: Maverick; mGluR: Metabotropic GluR; MTG: Mind-The-Gap; Munc/Unc: Mammalian uncoordinated/uncoordinated; NMDA: N-methyl-D-aspartate; NMJ: Neuromuscular junction; PAK/Pak: p21activated kinase; PDZ: PSD protein, DLG, zonula occludens-1 protein; PNS: Peripheral nervous system; PSD: Postsynaptic density; PTV: Piccolo/ Bassoon transport vesicles; RIM: Rab interacting molecule; RIM-BP: RIMbinding protein; RPTP: Receptor protein tyrosine phosphatase; RRP: Readily releasable pool; SAM: Sterile-a-motif; SAM: Substrate adhesion molecules; Sax: Saxophone; Sdc: Syndecan; SM: Sec1/Munc18-like; SMA: Spinal muscular atrophy-associated; SMN: Survival motor neuron; SNARE: Soluble Nethylmaleimide-sensitive factor activating protein receptor; SSR: Subsynaptic reticulum; STED: Stimulated emission depletion; SV: Synaptic vesicle; SVP: SV precursor; Syd: Synapse-defective; Syt: Synaptotagmin; Ten: Teneurin; TGF$\beta$ : Transforming growth factor $\beta$; Tkv: Thickveins; Wit: Wishful Thinking; Wnt/ Wg: Wingless Int-1/Wingless

\section{Acknowledgements}

We thank members of the Van Vactor lab for helpful discussions. We thank Elizabeth Benecchi at the Electron Microscopy Facility at Harvard Medical School for technical assistance with the electron micrograph displayed in Fig. 3a.

\section{Authors' contributions}

V.T.C. wrote the primary manuscript under the supervision of D.V.V. Follwing peer review, V.T.C. and S.A.J. contributed to the editing and revision of the 
manuscript and to the conceptual design and revision of figures. The authors read and approved the final manuscript.

\section{Funding}

This work was supported by the National Institutes of Health (F31

NS101756-03 to V.T.C., 5P01NS090994 to S.A.J. and D.V.V.).

\section{Availability of data and materials}

Not applicable.

\section{Ethics approval and consent to participate}

Not applicable.

\section{Consent for publication}

Not applicable.

\section{Competing interests}

The authors declare that they have no competing interests.

Received: 4 May 2020 Accepted: 14 July 2020

Published online: 02 August 2020

\section{References}

1. Saleeba C, Dempsey B, Le S, Goodchild A, McMullan S. A Student's guide to neural circuit tracing. Front Neurosci. 2019;13:1-19.

2. Herculano-Houzel $S$. The human brain in numbers: a linearly scaled-up primate brain. Front Hum Neurosci. 2009;3:31.

3. Colón-Ramos DA. Synapse formation in developing neural circuits. Curr Top Dev Biol. 2009;87(09):53-79.

4. Comer JD, Alvarez S, Butler SJ, Kaltschmidt JA. Commissural axon guidance in the developing spinal cord: from Cajal to the present day. Neural Dev. 2019;14(1):1-16.

5. Chia PH, Li P, Shen K. Cell biology in neuroscience: cellular and molecular mechanisms underlying presynapse formation. J Cell Biol. 2013;203(1):11-22.

6. Jessell TM, Kandel ER. Synaptic transmission: a bidirectional and selfmodifiable form of cell-cell communication. Cell. 1993;72(1):1-30.

7. Südhof TC. Towards an understanding of synapse formation. Neuron. 2018; 100(2):276-93.

8. Cammarata GM, Bearce EA, Lowery LA. Cytoskeletal social networking in the growth cone: how +TIPs mediate microtubule-actin cross-linking to drive axon outgrowth and guidance. Cytoskeleton. 2016;73(9):461-76.

9. Lowery LA, Van Vactor D. The trip of the tip: understanding the growth cone machinery. Nat Rev Mol Cell Biol. 2009;10(5):332-43.

10. Jin Y, Garner CC. Molecular mechanisms of presynaptic differentiation. Annu Rev Cell Dev Biol. 2008;24:237-62

11. Ackermann F, Waites CL, Garner CC. Presynaptic active zones in invertebrates and vertebrates. EMBO Rep. 2015;16(8):923-38.

12. Südhof TC. The presynaptic active zone. Neuron. 2012;75(1):11-25.

13. Zhai RG, Bellen HJ. The architecture of the active zone in the presynaptic nerve terminal. Physiology. 2004;19(5):262-70.

14. Ehmann N, Owald D, Kittel RJ. Drosophila active zones: from molecules to behaviour. Neurosci Res. 2018;127:14-24Available from:. https://doi.org/10. 1016/j.neures.2017.11.015.

15. Sheng M, Kim E. The postsynaptic organization of synapses. Cold Spring Harb Perspect Biol. 2011;3(12):a005678.

16. Scannevin $\mathrm{RH}$, Huganir RL. Postsynaptic organisation and regulation of excitatory synapses. Nat Rev Neurosci. 2000;1(2):133-41.

17. Sheng M, Kim MJ. Postsynaptic signaling and plasticity mechanisms. Science (80- ). 2002;298(5594):776-80

18. Van Vactor D, Sigrist SJ. Presynaptic morphogenesis, active zone organization and structural plasticity in drosophila. Curr Opin Neurobiol. 2017;43:119-29 [cited 2020 Feb 10]. Available from: http://www.ncbi.nlm. nih.gov/pubmed/28388491.

19. Rushton E, Rohrbough J, Broadie K. Presynaptic secretion of mind-the-gap organizes the synaptic extracellular matrix-integrin interface and postsynaptic environments. Dev Dyn. 2009;238(3):554-71.

20. Collins CA, DiAntonio A. Synaptic development: insights from drosophila. Curr Opin Neurobiol. 2007;17(1):35-42

21. Kohsaka H, Okusawa S, Itakura Y, Fushiki A, Nose A. Development of larval motor circuits in drosophila. Dev Growth Differ. 2012;54(3):408-19.
22. Kohsaka H, Guertin PA, Nose A. Neural circuits underlying Fly larval locomotion. Curr Pharm Des. 2017;23(12):1722-33.

23. Keshishian H, Kim YS. Orchestrating development and function: retrograde BMP signaling in the drosophila nervous system. Trends Neurosci. 2004. 27(3):143-7.

24. Bayat $\mathrm{V}$, Jaiswal M, Bellen HJ. The BMP signaling pathway at the drosophila neuromuscular junction and its links to neurodegenerative diseases. Curr Opin Neurobiol. 2011;21(1):182-8.

25. Speese SD, Budnik V. Wnts: up-and-coming at the synapse. Trends Neurosci. 2007;30(6):268-75

26. Koles K, Budnik V. Wnt signaling in neuromuscular junction development. Cold Spring Harb Perspect Biol. 2012;4(6):1-22.

27. Packard M, Koo ES, Gorczyca M, Sharpe J, Cumberledge S, Budnik V. The drosophila Wnt, wingless, provides an essential signal for pre- and postsynaptic differentiation. Cell. 2002;111(3):319-30.

28. Sen A, Yokokura T, Kankel MW, Dimlich DN, Manent J, Sanyal S, et al. Modeling spinal muscular atrophy in drosophila links Smn to FGF signaling. J Cell Biol. 2011;192(3):481-95.

29. Han KA, Jeon S, Um JW, Ko J. Emergent synapse organizers: LAR-RPTPs and their companions. Int Rev Cell Mol Biol. 2016;324:39-65.

30. Um JW, Ko J. LAR-RPTPs: synaptic adhesion molecules that shape synapse development. Trends Cell Biol. 2013;23(10):465-75.

31. Johnson KG, Tenney AP, Ghose A, Duckworth AM, Higashi ME, Parfitt K, et al. The HSPGs Syndecan and Dallylike bind the receptor phosphatase LAR and exert distinct effects on synaptic development. Neuron. 2006;49(4):517-31.

32. Dunah AW, Hueske E, Wyszynski M, Hoogenraad CC, Jaworski J, Pak DT, et al. LAR receptor protein tyrosine phosphatases in the development and maintenance of excitatory synapses. Nat Neurosci. 2005;8(4):458-67.

33. Petanjek $Z$, Judaš $M$, Šimić $G$, Rašin MR, Uylings HBM, Rakic $P$, et al. Extraordinary neoteny of synaptic spines in the human prefrontal cortex. Proc Natl Acad Sci U S A. 2011;108(32):13281-6.

34. Kandel ER. The molecular biology of memory storage: a dialogue between genes and synapses. Science (80- ). 2001;294(5544):1030-8.

35. Bailey CH, Kandel ER, Harris KM. Structural components of synaptic plasticity and memory consolidation. Cold Spring Harb Perspect Biol. 2015;7(7):1-29.

36. Thalhammer A, Cingolani LA. Cell adhesion and homeostatic synaptic plasticity. Neuropharmacology. 2014;78:23-30.

37. Giagtzoglou N, Ly C V., Bellen HJ. Cell adhesion, the backbone of the synapse: "vertebrate" and "invertebrate" perspectives. Cold Spring Harb Perspect Biol. 2009;1(4):a003079.

38. Hagler DJ, Goda Y. Synaptic adhesion: the building blocks of memory? Neuron. 1998;20(6):1059-62.

39. Lai KO, Ip NY. Synapse development and plasticity: roles of ephrin/Eph receptor signaling. Curr Opin Neurobiol. 2009;19(3):275-83.

40. Singh A, Winterbottom E, Daar IO. Eph/ephrin signaling in cell-cell and cellsubstrate adhesion. Front Biosci. 2012;17(2):473-97.

41. Sun MK, Xie W. Cell adhesion molecules in drosophila synapse development and function. Sci China Life Sci. 2012;55(1):20-6.

42. Biederer T, Sara Y, Mozhayeva M, Atasoy D, Liu X, Kavalali ET, et al. SynCAM, a synaptic adhesion molecule that drives synapse assembly. Science (80- ). 2002;297(5586):1525-31.

43. Fogel Al, Akins MR, Krupp AJ, Stagi M, Stein V, Biederer T. SynCAMs organize synapses through heterophilic adhesion. J Neurosci. 2007;27(46):12516-30.

44. Frei JA, Andermatt I, Gesemann M, Stoeckli ET. The SynCAM synaptic cell adhesion molecules are involved in sensory axon pathfinding by regulating axon-axon contacts. J Cell Sci. 2014;127(24):5288-302.

45. Brasch J, Katsamba PS, Harrison OJ, Ahlsén G, Troyanovsky RB, Indra I, et al. Homophilic and Heterophilic interactions of type II Cadherins identify specificity groups underlying cell-adhesive behavior. Cell Rep. 2018;23(6): 1840-52.

46. Ounkomol C, Yamada S, Heinrich V. Single-cell adhesion tests against functionalized microspheres arrayed on AFM cantilevers confirm heterophilic E- and N-cadherin binding. Biophys J. 2010;99(12):L100-2.

47. Prakasam AK, Maruthamuthu V, Leckband DE. Similarities between heterophilic and homophilic cadherin adhesion. Proc Natl Acad Sci U S A. 2006:103(42):15434-9.

48. Basu R, Taylor MR, Williams ME. The classic cadherins in synaptic specificity. Cell Adh Migr. 2015;9(3):193-201.

49. Lüthi A, Laurent JP, Figurovt A, Mullert D, Schachnert M. Hippocampal longterm potentiation and neural cell adhesion molecules L1 and NCAM. Nature. 1994;372(6508):777-9. 
50. Muller D, Wang C, Skibo G, Toni N, Cremer H, Calaora V, et al. PSA-NCAM is required for activity-induced synaptic plasticity. Neuron. 1996;17(3):413-22.

51. Schuster CM, Davis GW, Fetter RD, Goodman CS. Genetic dissection of structural and functional components of synaptic plasticity. I. Fasciclin II controls synaptic stabilization and growth. Neuron. 1996;17(4):641-54.

52. Davis GW, Schuster CM, Goodman CS. Genetic analysis of the mechanisms controlling target selection: target-derived Fasciclin II regulates the pattern of synapse formation. Neuron. 1997;19(3):561-73.

53. Beumer K, Matthies HJG, Bradshaw A, Broadie K. Integrins regulate DLG/ FAS2 via a CaM kinase II-dependent pathway to mediate synapse elaboration and stabilization during postembryonic development. Development. 2002;129(14):3381-91.

54. Agarwala KL, Ganesh S, Amano K, Suzuki T, Yamakawa K. DSCAM, a highly conserved gene in mammals, expressed in differentiating mouse brain. Biochem Biophys Res Commun. 2001;281(3):697-705.

55. Agarwala KL, Nakamura S, Tsutsumi Y, Yamakawa K. Down syndrome cell adhesion molecule DSCAM mediates homophilic intercellular adhesion. Mol Brain Res. 2000;79(1-2):118-26.

56. Suzuki SC, Takeichi M. Cadherins in neuronal morphogenesis and function. Dev Growth Differ. 2008;50(Suppl 1):S119-30.

57. Hirano S, Takeichi M. Cadherins in brain morphogenesis and wiring. Physiol Rev. 2012;92(2):597-634.

58. Brigidi GS, Bamji SX. Cadherin-catenin adhesion complexes at the synapse. Curr Opin Neurobiol. 2011;21(2):208-14.

59. Seong E, Yuan L, Arikkath J. Cadherins and catenins in dendrite and synapse morphogenesis. Cell Adh Migr. 2015;9(3):202-13.

60. Yamagata M, Herman JP, Sanes JR. Lamina-specific expression of adhesion molecules in developing chick optic tectum. J Neurosci. 1995;15(6):4556-71.

61. Uchida N, Honjo Y, Johnson KR, Wheelock MJ, Takeichi M. The catenin/ cadherin adhesion system is localized in synaptic junctions bordering transmitter release zones. J Cell Biol. 1996;135(3):767-79.

62. Yam PT, Pincus Z, Gupta GD, Bashkurov M, Charron F, Pelletier L, et al. Ncadherin relocalizes from the periphery to the center of the synapse after transient synaptic stimulation in hippocampal neurons. PLoS One. 2013; 8(11):1-12.

63. Vitureira N, Letellier M, White IJ, Goda Y. Differential control of presynaptic efficacy by postsynaptic $\mathrm{N}$-cadherin and $\beta$-catenin. Nat Neurosci. 2012;15(1): $81-9$.

64. Jüngling K, Eulenburg V, Moore R, Kemler R, Lessmann V, Gottmann K. Ncadherin transsynaptically regulates short-term plasticity at glutamatergic synapses in embryonic stem cell-derived neurons. J Neurosci. 2006;26(26): 6968-78.

65. Togashi H, Abe K, Mizoguchi A, Takaoka K, Chisaka O, Takeichi M. Cadherin regulates dendritic spine morphogenesis. Neuron. 2002;35(1):77-89.

66. Abe K, Chisaka O, Van Roy F, Takeichi M. Stability of dendritic spines and synaptic contacts is controlled by aN-catenin. Nat Neurosci. 2004;7(4):357-63.

67. Mendez P, De Roo M, Poglia L, Klauser P, Muller D. N-cadherin mediates plasticity-induced long-term spine stabilization. J Cell Biol. 2010;189(3):589-600.

68. Okamura K, Tanaka H, Yagita Y, Saeki Y, Taguchi A, Hiraoka Y, et al. Cadherin activity is required for activity-induced spine remodeling. J Cell Biol. 2004; 167(5):961-72

69. Bozdagi O, Bin WX, Nikitczuk JS, Anderson TR, Bloss EB, Radice GL, et al. Persistence of coordinated long-term potentiation and dendritic spine enlargement at mature hippocampal CA1 synapses requires $\mathrm{N}$-cadherin. J Neurosci. 2010;30(30):9984-9.

70. Bozdagi O, Shan W, Tanaka H, Benson DL, Huntley GW. Increasing numbers of synaptic puncta during late-phase LTP: N-cadherin is synthesized, recruited to synaptic sites, and required for potentiation. Neuron. 2000;28(1):245-59.

71. Ashley J, Packard M, Ataman B, Budnik V. Fasciclin II signals new synapse formation through amyloid precursor protein and the scaffolding protein dX11/mint. J Neurosci. 2005;25(25):5943-55.

72. Yu H-H, Yang JS, Wang J, Huang Y, Lee T. Endodomain diversity in the drosophila Dscam and its roles in neuronal morphogenesis. J Neurosci. 2009;29(6):1904-14.

73. Wang J, Zugates $C T$, Liang $\mathbb{H}_{\text {, Lee }} \mathrm{CHJ}$, Lee $\mathrm{T}$. Drosophila Dscam is required for divergent segregation of sister branches and suppresses ectopic bifurcation of axons. Neuron. 2002;33(4):559-71.

74. Hutchinson KM, Vonhoff F, Duch C. Dscam1 is required for Normal dendrite growth and branching but not for dendritic spacing in drosophila Motoneurons. J Neurosci. 2014;34(5):1924-31.
75. Spring AM, Brusich DJ, Frank CA. C-terminal Src kinase gates homeostatic synaptic plasticity and regulates Fasciclin II expression at the drosophila neuromuscular junction. PLoS Genet. 2016;12(2):1-31.

76. Kohsaka H, Takasu E, Nose A. In vivo induction of postsynaptic molecular assembly by the cell adhesion molecule Fasciclin2. J Cell Biol. 2007;179(6): 1289-300.

77. Mayford M, Barzilai A, Keller F, Schacher S, Kandel ER. Modulation of an NCAM-related adhesion molecule with long-term synaptic plasticity in aplysia. Science (80- ). 1992;256(5057):638-44.

78. Knight D, Xie W, Boulianne GL. Neurexins and neuroligins: recent insights from invertebrates. Mol Neurobiol. 2011;44(3):426-40.

79. Craig AM, Kang Y. Neurexin-neuroligin signaling in synapse development. Curr Opin Neurobiol. 2007;17(1):43-52.

80. Bottos A, Rissone A, Bussolino F, Arese M. Neurexins and neuroligins: synapses look out of the nervous system. Cell Mol Life Sci. 2011;68(16): 2655-66.

81. Südhof TC. Neuroligins and neurexins link synaptic function to cognitive disease. Nature. 2008;455(7215):903-11.

82. Mosca TJ. On the Teneurin track: a new synaptic organization molecule emerges. Front Cell Neurosci. 2015;9:1-14.

83. Tucker RP, Chiquet-Ehrismann R. Teneurins: a conserved family of transmembrane proteins involved in intercellular signaling during development. Dev Biol. 2006;290(2):237-45.

84. Zinn K, Özkan E. Neural immunoglobulin superfamily interaction networks Curr Opin Neurobiol. 2017:45:99-105.

85. Morey M. Dpr-DIP matching expression in drosophila synaptic pairs. Fly (Austin). 2017;11(1):19-26.

86. Graf ER, Zhang X, Jin SX, Linhoff MW, Craig AM. Neurexins induce differentiation of GABA and glutamate postsynaptic specializations via neuroligins. Cell. 2004;119(7):1013-26.

87. Scheiffele P, Fan J, Choih J, Fetter R, Serafini T. Neuroligin expressed in nonneuronal cells triggers presynaptic development in contacting axons. Cell. 2000;101(6):657-69.

88. Varoqueaux F, Aramuni G, Rawson RL, Mohrmann R, Missler M, Gottmann K, et al. Neuroligins determine synapse maturation and function. Neuron. 2006:51(6):741-54

89. Li J, Ashley J, Budnik V, Bhat MA. Crucial role of drosophila Neurexin in proper active zone apposition to postsynaptic densities, synaptic growth, and synaptic transmission. Neuron. 2007;55(5):741-55.

90. Chen K, Gracheva EO, Yu SC, Sheng Q, Richmond J, Featherstone DE. Neurexin in embryonic drosophila neuromuscular junctions. PLoS One. 2010;5(6):e11115.

91. Etherton MR, Blaiss CA, Powell CM, Südhof TC. Mouse neurexin-1a deletion causes correlated electrophysiological and behavioral changes consistent with cognitive impairments. Proc Natl Acad Sci U S A. 2009;106(42):17998-8003.

92. Chen LY, Jiang M, Zhang B, Gokce O, Südhof TC. Conditional deletion of all Neurexins defines diversity of essential synaptic organizer functions for Neurexins. Neuron. 2017;94(3):611-625.e4

93. Owald D, Khorramshahi O, Gupta VK, Banovic D, Depner H, Fouquet W, et al. Cooperation of Syd-1 with Neurexin synchronizes pre- with postsynaptic assembly. Nat Neurosci. 2012;15(9):1219-26.

94. Banerjee S, Venkatesan A, Bhat MA. Neurexin, Neuroligin and wishful thinking coordinate synaptic cytoarchitecture and growth at neuromuscular junctions. Mol Cell Neurosci. 2017;78:9-24.

95. Chih B, Engelman H, Scheiffele P. Control of excitatory and inhibitory synapse formation by neuroligins. Science (80- ). 2005;307(5713):1324-8.

96. Chubykin AA, Atasoy D, Etherton MR, Brose N, Kavalali ET, Gibson JR, et al. Activity-dependent validation of excitatory versus inhibitory synapses by Neuroligin-1 versus Neuroligin-2. Neuron. 2007;54(6):919-31.

97. Chen Y-C, Lin YQ, Banerjee S, Venken K, Li J, Ismat A, et al. Drosophila Neuroligin 2 is required Presynaptically and Postsynaptically for proper synaptic differentiation and synaptic transmission. J Neurosci. 2012;32(45):16018-30.

98. Banovic D, Khorramshahi O, Owald D, Wichmann C, Riedt T, Fouquet W, et al. Drosophila Neuroligin 1 promotes growth and postsynaptic differentiation at glutamatergic neuromuscular junctions. Neuron. 2010;66(5):724-38.

99. Xing G, Li M, Sun Y, Rui M, Zhuang Y, Lv H, et al. Neurexin-neuroligin 1 regulates synaptic morphology and functions via the WAVE regulatory complex in drosophila neuromuscular junction. Elife. 2018;7:1-23.

100. Baumgartner S, Littleton JT, Broadie K, Bhat MA, Harbecke R, Lengyel JA, et al. A drosophila neurexin is required for septate junction and bloodnerve barrier formation and function. Cell. 1996;87(6):1059-68. 
101. Bellen HJ, Lu Y, Beckstead R, Bhat MA. Neurexin IV, caspr and paranodin novel members of the neurexin family: encounters of axons and glia. Trends Neurosci. 1998;21(10):444-9.

102. Peles E, Nativ M, Lustig M, Grumet M, Schilling J, Martinez R, et al. Identification of a novel contactin-associated transmembrane receptor with multiple domains implicated in protein-protein interactions. EMBO J. 1997: 16(5):978-88.

103. Böhme MA, Beis C, Reddy-Alla S, Reynolds E, Mampell MM, Grasskamp AT, et al. Active zone scaffolds differentially accumulate Unc13 isoforms to tune Ca2+ channel-vesicle coupling. Nat Neurosci. 2016;19(10):1311-20.

104. Maruyama IN, Brenner S. A phorbol ester/diacylglycerol-binding protein encoded by the unc-13 gene of Caenorhabditis elegans. Proc Natl Acad Sci. 1991;88(13):5729-33

105. Lai Y, Choi UB, Leitz J, Rhee HJ, Lee C, Altas B, et al. Molecular mechanisms of synaptic vesicle priming by Munc13 and Munc18. Neuron. 2017;95(3): 591-607.e10.

106. Rosenmund C, Sigler A, Augustin I, Reim K, Brose N, Rhee JS. Differential control of vesicle priming and short-term plasticity by Munc13 isoforms. Neuron. 2002;33(3):411-24.

107. Zweier C, de Jong EK, Zweier M, Orrico A, Ousager LB, Collins AL, et al. CNTNAP2 and NRXN1 are mutated in autosomal-recessive Pitt-Hopkins-like mental retardation and determine the level of a common synaptic protein in drosophila. Am J Hum Genet. 2009;85(5):655-66.

108. McNeill EM, Warinner C, Alkins S, Taylor A, Heggeness H, DeLuca TF, et al. The conserved microRNA miR-34 regulates synaptogenesis via coordination of distinct mechanisms in presynaptic and postsynaptic cells. Nat Commun. 2020;11(1):1092.

109. Leamey CA, Sawatari A. The teneurins: new players in the generation of visual topography. Semin Cell Dev Biol. 2014;35:173-9.

110. Mosca TJ, Hong W, Dani VS, Favaloro V, Luo L. Trans-synaptic Teneurin signalling in neuromuscular synapse organization and target choice. Nature. 2012:484(7393):237-41.

111. Ataman B, Ashley J, Gorczyca M, Ramachandran P, Fouquet W, Sigrist SJ, et al. Rapid activity-dependent modifications in synaptic structure and function require bidirectional Wnt signaling. Neuron. 2008;57:705-18.

112. Piccioli ZD, Littleton JT. Retrograde BMP signaling modulates rapid activitydependent synaptic growth via presynaptic LIM kinase regulation of cofilin. J Neurosci. 2014;34(12):4371-81.

113. Berke B, Wittnam J, McNeill E, Van Vactor DL, Keshishian H. Retrograde BMP signaling at the synapse: a permissive signal for synapse maturation and activity-dependent plasticity. J Neurosci. 2013;33(45):17937-50.

114. Zito K, Parnas D, Fetter RD, Isacoff EY, Goodman CS. Watching a synapse grow: noninvasive confocal imaging of synaptic growth in drosophila. Neuron. 1999;22(4):719-29.

115. Fuentes-Medel Y, Logan MA, Ashley J, Ataman B, Budnik V, Freeman MR. Glia and muscle sculpt neuromuscular arbors by engulfing destabilized synaptic boutons and shed presynaptic debris. PLoS Biol. 2009;7(8): e1000184.

116. Johansen J, Halpern M, Johansen K, Keshishian H. Stereotypic morphology of glutamatergic synapses on identified muscle cells of drosophila larvae. J Neurosci. 1989;9(2):710-25.

117. Hoang B, Chiba A. Single-cell analysis of drosophila larval neuromuscular synapses. Dev Biol. 2001;229(1):55-70.

118. Ataman B, Ashley J, Gorczyca D, Gorczyca M, Mathew D, Wichmann C, et al. Nuclear trafficking of drosophila Frizzled-2 during synapse development requires the PDZ protein dGRIP. Proc Natl Acad Sci U S A. 2006;103(20):7841-6.

119. Vasin A, Zueva L, Torrez C, Volfson D, Littleton JT, Bykhovskaia M. Synapsin regulates activity-dependent outgrowth of synaptic boutons at the drosophila neuromuscular junction. J Neurosci. 2014:34(32):10554-63.

120. Kaufmann N, DeProto J, Ranjan R, Wan H, Van Vactor D. Drosophila liprinalpha and the receptor phosphatase Dlar control synapse morphogenesis. Neuron. 2002;34(1):27-38.

121. Miller K, Chou VT, Van Vactor D. Liprin-a and assembly of the synaptic Cytomatrix. In: Reference module in neuroscience and biobehavioral psychology. Basel: Elsevier; 2017. p. 1-8.

122. Owald D, Fouquet W, Schmidt M, Wichmann C, Mertel S, Depner H, et al. A Syd-1 homologue regulates pre- and postsynaptic maturation in drosophila. J Cell Biol. 2010;188(4):565-79.

123. Dai Y, Taru H, Deken SL, Grill B, Ackley B, Nonet ML, et al. SYD-2 Liprina organizes presynaptic active zone formation through ELKS. Nature Neuroscience; 2006;9(12):1479-87.
124. Patel MR, Lehrman EK, Poon VY, Crump JG, Zhen M, Bargmann Cl, et al. Hierarchical assembly of presynaptic components in defined C. elegans synapses. Nat Neurosci. 2006;9(12):1488-98.

125. Wentzel C, Sommer JE, Nair R, Stiefvater A, Sibarita JB, Scheiffele P. MSYD1A, a mammalian synapse-Defective-1 protein, regulates Synaptogenic signaling and vesicle docking. Neuron. 2013;78(6):1012-23.

126. Phillips GR, Huang JK, Wang Y, Tanaka H, Shapiro L, Zhang W, et al. The presynaptic particle web: ultrastructure, composition, dissolution, and reconstitution. Neuron. 2001;32(1):63-77.

127. Chakrabarti R, Wichmann C. Nanomachinery organizing release at neuronal and ribbon synapses. Int J Mol Sci. 2019;20(9):23-32.

128. Lenzi D, Von Gersdorff $H$. Structure suggests function: the case for synaptic ribbons as exocytotic nanomachines. BioEssays. 2001;23(9):831-40.

129. Muresan V, Lyass A, Schnapp BJ. The kinesin motor KIF3A is a component of the presynaptic ribbon in vertebrate photoreceptors. J Neurosci. 1999;19(3):1027-37.

130. Harlow ML, Ress D, Stoschek A, Marshall RM, McMahan UJ. The architecture of active zone material at the frog's neuromuscular junction. Nature. 2001; 409(6819):479-84.

131. Jiao W, Masich S, Franzén O, Shupliakov O. Two pools of vesicles associated with the presynaptic cytosolic projection in drosophila neuromuscular junctions. J Struct Biol. 2010:172(3):389-94.

132. Goldstein AYN, Wang X, Schwarz TL. Axonal transport and the delivery of pre-synaptic components. Curr Opin Neurobiol. 2008;18(5):495-503.

133. Maeder Cl, Shen K, Hoogenraad CC. Axon and dendritic trafficking. Curr Opin Neurobiol. 2014;27:165-70.

134. Pack-Chung E, Kurshan PT, Dickman DK, Schwarz TL. A drosophila kinesin required for synaptic Bouton formation and synaptic vesicle transport. Nat Neurosci. 2007:10(8):980-9.

135. Pilling AD, Horiuchi D, Lively CM, Saxton WM. Kinesin-1 and dynein are the primary Motors for Fast Transport of mitochondria in drosophila motor axons. Mol Biol Cell. 2006;17(4):2057-68.

136. Hurd DD, Saxton WM. Kinesin mutations cause motor neuron disease phenotypes by disrupting fast axonal transport in drosophila. Genetics. 1996;144(3):1075-85.

137. Miller KE, Heidemann SR. What is slow axonal transport? Exp Cell Res. 2008; 314(10):1981-90.

138. Popov S, Poo MM. Diffusional transport of macromolecules in developing nerve processes. J Neurosci. 1992;12(1):77-85.

139. Shapira M, Zhai RG, Dresbach T, Bresler T, Torres VI, Gundelfinger ED, et al. Unitary assembly of presynaptic active zones from piccolo-bassoon transport vesicles. Neuron. 2003;38(2):237-52.

140. Zhai RG, Vardinon-Friedman H, Cases-Langhoff C, Becker B, Gundelfinger ED, Ziv NE, et al. Assembling the presynaptic active zone: a characterization of an active one precursor vesicle. Neuron. 2001;29(1):131-43.

141. Tao-Cheng JH. Ultrastructural localization of active zone and synaptic vesicle proteins in a preassembled multi-vesicle transport aggregate. Neuroscience. 2007:150(3):575-84

142. Ziv NE, Garner CC. Cellular and molecular mechanisms of presynaptic assembly. Nat Rev Neurosci. 2004;5(5):385-99.

143. Waites CL, Craig AM, Garner CC. Mechanisms of vertebrate synaptogenesis. Annu Rev Neurosci. 2005:28(1):251-74.

144. Bury LAD, Sabo SL. Coordinated trafficking of synaptic vesicle and active zone proteins prior to synapse formation. Neural Dev. 2011;6(1):1-14.

145. Wu YE, Huo L, Maeder Cl, Feng W, Shen K. The balance between capture and dissociation of presynaptic proteins controls the spatial distribution of synapses. Neuron. 2013;78(6):994-1011.

146. Lipton DM, Maeder Cl, Shen K. Rapid assembly of presynaptic materials behind the growth cone in dopaminergic neurons is mediated by precise regulation of axonal transport. Cell Rep. 2018;24(10):2709-22.

147. Petzoldt AG, Lützkendorf J, Sigrist SJ. Mechanisms controlling assembly and plasticity of presynaptic active zone scaffolds. Curr Opin Neurobiol. 2016:39:69-76.

148. Vukoja A, Rey U, Petzoldt AG, Ott C, Vollweiter D, Quentin C, et al. Presynaptic biogenesis requires axonal transport of lysosome-related vesicles. Neuron. 2018;99(6):1216-1232.e7.

149. Fouquet W, Owald D, Wichmann C, Mertel S, Depner H, Dyba M, et al. Maturation of active zone assembly by drosophila Bruchpilot. J Cell Biol. 2009;186(1):129-45.

150. Zhen $M_{1}$ Jin $Y$. The liprin protein SYD-2 regulates the differentiation of presynaptic termini in C. elegans. Nature. 1999;401(6751):371-5.

151. Astigarraga $S$, Hofmeyer $K$, Farajian $R$, Treisman JE. Three drosophila liprins interact to control synapse formation. J Neurosci. 2010;30(46):15358-68. 
152. Stigloher C, Zhan H, Zhen M, Richmond J, Bessereau J-L. The presynaptic dense projection of the Caenorhabiditis elegans cholinergic neuromuscular junction localizes synaptic vesicles at the active zone through SYD-2/Liprin and UNC-10/RIM-dependent interactions. J Neurosci. 2011;31(12):4388-96.

153. Spinner MA, Walla DA, Herman TG. Drosophila syd-1 has rhogap activity that is required for presynaptic clustering of bruchpilot/elks but not neurexin-1. Genetics. 2018;208(2):705-16.

154. Li L, Tian X, Zhu M, Bulgari D, Böhme MA, Goettfert F, et al. Drosophila Syd1, Liprin- $a$, and protein phosphatase 2A B' subunit Wrd function in a linear pathway to prevent ectopic accumulation of synaptic materials in distal axons. J Neurosci. 2014;34(25):8474-87.

155. Hallam SJ, Goncharov A, McEwen J, Baran R, Jin Y. SYD-1, a presynaptic protein with PDZ, C2 and rhoGAP-like domains, specifies axon identity in C. elegans. Nat Neurosci. 2002;5(11):1137-46.

156. Spangler SA, Hoogenraad CC. Liprin-alpha proteins: scaffold molecules for synapse maturation. Biochem Soc Trans. 2007;35(Pt 5):1278-82.

157. Serra-Pagès C, Medley QG, Tang M, Hart A, Streuli M. Liprins, a family of LAR transmembrane protein-tyrosine phosphatase- interacting proteins. J Biol Chem. 1998;273(25):15611-20.

158. Serra-Pagès C, Kedersha NL, Fazikas L, Medley Q, Debant A, Streuli M. The LAR transmembrane protein tyrosine phosphatase and a coiled-coil LAR-interacting protein co-localize at focal adhesions. EMBO J. 1995;14(12):2827-38.

159. Brose N, Hofmann K, Hata Y, Sudhof TC. Mammalian homologues of Caenorhabditis elegans unc-13 gene define novel family of C2-domain proteins. J Biol Chem. 1995;270(42):25273-80.

160. Augustin I, Rosenmund C, Südhof TC, Brose N. Munc13-1 is essential for fusion competence of glutamatergic synaptic vesicles. Nature. 1999; 400(6743):457-61.

161. Palfreyman MT, Jorgensen EM. Unc13 aligns SNAREs and Superprimes synaptic vesicles. Neuron. 2017;95(3):473-5.

162. Xu J, Camacho M, Xu Y, Esser V, Liu X, Trimbuch T, et al. Mechanistic insights into neurotransmitter release and presynaptic plasticity from the crystal structure of Munc13-1 C1C2BMUN. Elife. 2017;6:e22567.

163. Wang Y, Okamoto M, Schmitz F, Hofmann K, Südhof TC. Rim is a putative rab3 effector in regulating synaptic-vesicle fusion. Nature. 1997;388(6642):593-8.

164. Mittelstaedt T, Alvaréz-Baron E, Schoch S. RIM proteins and their role in synapse function. Biol Chem. 2010;391(6):599-606.

165. Lu J, Machius M, Dulubova I, Dai H, Südhof TC, Tomchick DR, et al. Structural basis for a Munc13-1 homodimer to Munc13-1/RIM heterodimer switch. PLoS Biol. 2006;4(7):1159-72.

166. Deng L, Kaeser PS, Xu W, Südhof TC. RIM proteins activate vesicle priming by reversing autoinhibitory homodimerization of munc13. Neuron. 2011;69(2):317-31.

167. Kaeser P. Pushing synaptic vesicles over the RIM. Cell Logist. 2011;1(3):106-10.

168. Castillo PE, Schoch S, Schmitz F, Südhof TC, Malenka RC. RIM1a is required for presynaptic long-term potentiation. Nature. 2002;415(6869):327-30.

169. Schoch S, Castillo PE, Jo T, Mukherjee K, Geppert M, Wang Y, et al. RIM1a forms a protein scaffold for regulating neurotransmitter release at the active zone. Nature. 2002;415(6869):321-6.

170. Graf ER, Valakh V, Wright CM, Wu C, Liu Z, Zhang YQ, et al. RIM promotes Calcium Channel accumulation at active zones of the drosophila neuromuscular junction. J Neurosci. 2012;32(47):16586-96.

171. Han Y, Babai N, Kaeser P, Südhof TC, Schneggenburger R. RIM1 and RIM2 redundantly determine ca $2+$ channel density and readily releasable pool size at a large hindbrain synapse. J Neurophysiol. 2015;113(1):255-63.

172. Kaeser PS, Deng L, Wang Y, Dulubova I, Liu X, Rizo J, et al. RIM proteins tether Ca2+ channels to presynaptic active zones via a direct PDZ-domain interaction. Cell. 2011;144(2):282-95.

173. Mittelstaedt T, Schoch S. Structure and evolution of RIM-BP genes: identification of a novel family member. Gene. 2007:403(1-2):70-9.

174. Wang Y, Sugita S, Südhof TC. The RIM/NIM family of neuronal C2 domain proteins: interactions with Rab3 and a new class of Src homology 3 domain proteins. J Biol Chem. 2000;275(26):20033-44.

175. Hibino H, Pironkova R, Onwumere O, Vologodskaia M, Hudspeth AJ, Lesage F. RIM binding proteins (RBPs) couple Rab3-interacting molecules (RIMs) to voltage-gated Ca2+ channels. Neuron. 2002;34(3):411-23.

176. Liu KSY, Siebert M, Mertel S, Knoche E, Wegener S, Wichmann C, et al. RIMbinding protein, a central part of the active zone, is essential for neurotransmitter release. Science. 2011;334(6062):1565-9.

177. Matkovic T, Siebert M, Knoche E, Depner H, Mertel S, Owald D, et al. The Bruchpilot cytomatrix determines the size of the readily releasable pool of synaptic vesicles. J Cell Biol. 2013;202(4):667-83.
178. Kittel RJ, Wichmann C, Rasse TM, Fouquet W, Schmidt M, Schmid A, et al. Bruchpilot promotes active zone assembly, Ca2+ channel clustering, and vesicle release. Science (80- ). 2006;312(5776):1051-4.

179. Wagh DA, Rasse TM, Asan E, Hofbauer A, Schwenkert I, Dürrbeck H, et al. Bruchpilot, a protein with homology to ELKS/CAST, is required for structural integrity and function of synaptic active zones in drosophila. Neuron. 2006; 49:833-44.

180. Sugie A, Hakeda-Suzuki S, Suzuki E, Silies M, Shimozono M, Möhl C, et al. Molecular remodeling of the presynaptic active zone of drosophila photoreceptors via activity-dependent feedback. Neuron. 20156;86(3):711-25.

181. Schmid A, Hallermann S, Kittel RJ, Khorramshahi O, Frölich AMJ, Quentin C, et al. Activity-dependent site-specific changes of glutamate receptor composition in vivo. Nat Neurosci. 2008;11(6):659-66.

182. Ehmann N, van de Linde S, Alon A, Ljaschenko D, Keung XZ, Holm T, et al. Quantitative super-resolution imaging of Bruchpilot distinguishes active zone states. Nat Commun. 2014:5:4650.

183. Sudhof TC. The synaptic vesicle cycle. Annu Rev Neurosci. 2004;27:509-47.

184. Held RG, Kaeser PS. ELKS active zone proteins as multitasking scaffolds for secretion. Open Biol. 2018;8(2):170258.

185. Kaeser PS, Regehr WG. The readily releasable pool of synaptic vesicles. Curr Opin Neurobiol. 2017:43(1):63-70.

186. Ge WP, Yang XJ, Zhang Z, Wang HK, Shen W, Deng QD, et al. Long-term potentiation of neuron-glia synapses mediated by Ca2+-permeable AMPA receptors. Science (80- ). 2006;312(5779):1533-7.

187. Jabs R, Pivneva T, Hüttmann K, Wyczynski A, Nolte C, Kettenmann H, et al. Synaptic transmission onto hippocampal glial cells with hGFAP promoter activity. J Cell Sci. 2005;118(16):3791-803.

188. Bergles DE, Roberts JDB, Somogyi P, Jahr CE. Glutamatergic synapses on OPCs in the hippocampus. Nature. 2000:405(1996):187-91.

189. Lin SC, Bergles DE. Synaptic signaling between neurons and glia. Glia. 2004; 47(3):290-8

190. Lin SC, Bergles DE. Synaptic signaling between GABAergic interneurons and oligodendrocyte precursor cells in the hippocampus. Nat Neurosci. 2004; 7(1):24-32.

191. Kennedy MB. Signal-processing machines at the postsynaptic density. Science (80- ). 2000;290(5492):750-4.

192. Palay SL. Synapses in the central nervous system. J Biophys Biochem Cytol. 1956;2(4 Suppl):193-202.

193. Gray EG. Axo-somatic and axo-dendritic synapses of the cerebral cortex: an electron microscope study. J Anat. 1959;93(4 Suppl):420-33.

194. Scheefhals N, MacGillavry HD. Functional organization of postsynaptic glutamate receptors. Mol Cell Neurosci. 2018;91:82-94.

195. DiAntonio A. Glutamate receptors at the drosophila neuromuscular junction. Int Rev Neurobiol. 2006;75(06):165-79.

196. Littleton JT. A genomic analysis of membrane trafficking and neurotransmitter release in drosophila. J Cell Biol. 2000;150(2):77-81.

197. Han TH, Dharkar P, Mayer ML, Serpe M. Functional reconstitution of Drosophila melanogaster NMJ glutamate receptors. Proc Natl Acad Sci U S A. 2015;112(19):6182-7.

198. Qin G, Schwarz T, Kittel RJ, Schmid A, Rasse TM, Kappei D, et al. Four different subunits are essential for expressing the synaptic glutamate receptor at neuromuscular junctions of drosophila. J Neurosci. 2005;25(12): 3209-18.

199. Featherstone DE, Rushton E, Rohrbough J, Liebl F, Karr J, Sheng Q, et al. An essential drosophila glutamate receptor subunit that functions in both central neuropil and neuromuscular junction. J Neurosci. 2005;25(12):3199-208.

200. Schuster CM, Ultsch A, Schloss P, Cox JA, Schmrrr B, Betzt H. Molecular cloning of an invertebrate glutamate receptor subunit expressed in drosophila muscle. Science. 2019:254(5028):112-4.

201. Marrus SB, DiAntonio A. Preferential localization of glutamate receptors opposite sites of high presynaptic release. Curr Biol. 2004;14(11):924-31.

202. Petersen SA, Fetter RD, Noordermeer JN, Goodman CS, DiAntonio A. Genetic analysis of glutamate receptors in drosophila reveals a retrograde signal regulating presynaptic transmitter release. Neuron. 1997;19(6):1237-48.

203. DiAntonio A, Petersen SA, Heckmann M, Goodman CS. Glutamate receptor expression regulates quantal size and quantal content at the drosophila neuromuscular junction. J Neurosci. 1999;19(8):3023-32.

204. Kim YJ, Igiesuorobo O, Ramos Cl, Bao H, Zhang B, Serpe M. Prodomain removal enables Neto to stabilize glutamate receptors at the drosophila neuromuscular junction. PLoS Genet. 2015;11(2):1-26. 
205. Kim YJ, Bao H, Bonanno L, Zhang B, Serpel M. Drosophila neto is essential for clustering glutamate receptors at the neuromuscular junction. Genes Dev. 2012;26(9):974-87.

206. Ramos Cl, lgiesuorobo O, Wang Q, Serpe M. Neto-mediated intracellular interactions shape postsynaptic composition at the drosophila neuromuscular junction. PLoS Genet. 2015;11(4):1-26.

207. Zhang W, St-Gelais F, Grabner CP, Trinidad JC, Sumioka A, Morimoto-Tomita $\mathrm{M}$, et al. A transmembrane accessory subunit that modulates Kainate-type glutamate receptors. Neuron. 2009;61(3):385-96

208. Ng D, Pitcher GM, Szilard RK, Sertié A, Kanisek M, Clapcote SJ, et al. Neto1 is a novel CUB-domain NMDA receptor-interacting protein required for synaptic plasticity and learning. PLoS Biol. 2009;7(2):0278-300.

209. Sigrist SJ, Thiel PR, Reiff DF, Schuster CM. The postsynaptic glutamate receptor subunit DGluR-IIA mediates long-term plasticity in drosophila. J Neurosci. 2002;22(17):7362-72.

210. Zhao Z, Manser E. PAK family kinases. Cell Logist. 2012;2(2):59-68.

211. Civiero L, Greggio E. PAKs in the brain: function and dysfunction. Biochim Biophys Acta - Mol Basis Dis. 2018;1864(2):444-53.

212. Sulkowski MJ, Han TH, Ott C, Wang Q, Verheyen EM, Lippincott-Schwartz J et al. A novel, noncanonical BMP pathway modulates synapse maturation at the drosophila neuromuscular junction. PLoS Genet. 2016;12(1):1-31.

213. Rasse TM, Fouquet W, Schmid A, Kittel RJ, Mertel S, Sigrist CB, et al. Glutamate receptor dynamics organizing synapse formation in vivo. Nat Neurosci. 2005;8(7):898-905.

214. Sone M, Suzuki E, Hoshino M, Hou D, Kuromi H, Fukata M, et al. Synaptic development is controlled in the periactive zones of drosophila synapses. Development. 2000;127(19):4157-68.

215. Wan HI, DiAntonio A, Fetter RD, Bergstrom K, Strauss R, Goodman CS. Highwire regulates synaptic growth in drosophila. Neuron. 2000;26(2):313-29.

216. Parnas D, Haghighi AP, Fetter RD, Kim SW, Goodman CS. Regulation of postsynaptic structure and protein localization by the rho-type guanine nucleotide exchange factor dPix. Neuron. 2001;32(3):415-24.

217. Albin SD, Davis GW. Coordinating structural and functional synapse development: postsynaptic p21-activated kinase independently specifies glutamate receptor abundance and postsynaptic morphology. J Neurosci. 2004:24(31):6871-9.

218. Teodoro RO, Pekkurnaz G, Nasser A, Higashi-Kovtun ME, Balakireva M, Mclachlan IG, et al. Ral mediates activity-dependent growth of postsynaptic membranes via recruitment of the exocyst. EMBO J. 2013;32(14):2039-55.

219. Quan A, Robinson PJ. Syndapin - a membrane remodelling and endocytic F-BAR protein. FEBS J. 2013;280(21):5198-212.

220. Kumar V, Fricke R, Bhar D, Reddy-Alla S, Krishnan KS, Bogdan S, et al. Syndapin promotes formation of a postsynaptic membrane system in drosophila. Mol Biol Cell. 2009;20:2254-64 Available from: http://www. molbiolcell.org/cgi/doi/10.1091/mbc. E08.

221. Kessels MM, Qualmann B. Syndapins integrate N-WASP in receptormediated endocytosis. EMBO J. 2002:21(22):6083-94.

222. Oh E, Robinson I. Barfly: sculpting membranes at the drosophila neuromuscular junction. Dev Neurobiol. 2012;72(1):33-56.

223. Wang S, Yang J, Tsai A, Kuca T, Sanny J, Lee J, et al. Drosophila adducin regulates Dlg phosphorylation and targeting of Dlg to the synapse and epithelial membrane. Dev Biol. 2011;357(2):392-403.

224. Wang SJH, Tsai A, Wang M, Yoo SH, Kim HY, Yoo B, et al. Phospho-regulated drosophila adducin is a determinant of synaptic plasticity in a complex with Dlg and PIP2 at the larval neuromuscular junction. Biol Open. 2014:3(12):1196-206.

225. Pielage J, Bulat V, Zuchero JB, Fetter RD, Davis GW. Hts/Adducin controls synaptic elaboration and elimination. Neuron. 2011;69(6):1114-31.

226. Loya CM, McNeill EM, Bao H, Zhang B, Van Vactor D. miR-8 controls synapse structure by repression of the actin regulator enabled. Development. 2014; 141(9):1864-74.

227. Pielage J, Fetter RD, Davis GW. A postsynaptic Spectrin scaffold defines active zone size, spacing, and efficacy at the drosophila neuromuscular junction. J Cell Biol. 2006;175(3):491-503.

228. Pielage J, Fetter RD, Davis GW. Presynaptic spectrin is essential for synapse stabilization. Curr Biol. 2005;15(10):918-28.

229. Pielage J, Cheng L, Fetter RD, Carlton PM, Sedat JW, Davis GW. A presynaptic giant ankyrin stabilizes the NMJ through regulation of presynaptic microtubules and transsynaptic cell adhesion. Neuron. 2008;58(2):195-209.

230. Koch I, Schwarz H, Beuchle D, Goellner B, Langegger M, Aberle $H$. Drosophila Ankyrin 2 is required for synaptic stability. Neuron. 2008:58(2): 210-22.
231. Tejedor FJ, Bokhari A, Rogero O, Gorczyca M, Zhang J, Kim E, et al. Essential role for dlg in synaptic clustering of shaker K+ channels in vivo. J Neurosci. 1997;17(1):152-9.

232. Thomas U, Kim E, Kuhlendahl S, Koh YH, Gundelfinger ED, Sheng M, et al. Synaptic clustering of the cell adhesion molecule Fasciclin II by discs-large and its role in the regulation of presynaptic structure. Neuron. 1997;19(4): 787-99.

233. Chen K, Featherston DE. Discs-large (DLG) is clustered by presynaptic innervation and regulates postsynaptic glutamate receptor subunit composition in drosophila. BMC Biol. 2005;3:1-13.

234. Rao A, Kim E, Sheng M, Craig AM. Heterogeneity in the molecular composition of excitatory postsynaptic sites during development of hippocampal neurons in culture. J Neurosci. 1998:18(4):1217-29.

235. Budnik V, Koh YH, Guan B, Hartmann B, Hough C, Woods D, et al. Regulation of synapse structure and function by the drosophila tumor suppressor gene dlg. Neuron. 1996;17(4):627-40

236. Astorga C, Jorquera RA, Ramírez M, Kohler A, López E, Delgado R, et al. Presynaptic DLG regulates synaptic function through the localization of voltage-activated Ca2+ channels. Sci Rep. 2016;6:1-14.

237. Hoogenraad CC, Feliu-Mojer MI, Spangler SA, Milstein AD, Dunah AW, Hung AY, et al. Liprina1 degradation by calcium/calmodulin-dependent protein kinase II regulates LAR receptor tyrosine phosphatase distribution and dendrite development. Dev Cell. 2007;12(4):587-602.

238. Mathew D, Ataman B, Chen J, Zhang Y, Cumberledge S, Budnik V. Cell signaling: wingless signaling at synapses is through cleavage and nuclear import of receptor DFrizzled2. Science (80- ). 2005;310(5752):1344-7.

239. Dear ML, Dani N, Parkinson W, Zhou S, Broadie K. Two classes of matrix metalloproteinases reciprocally regulate synaptogenesis. Dev. 2016;143(1): 75-87 [cited 2020 Jun 21]. Available from: https://pubmed.ncbi.nlm.nih. gov/26603384/.

240. Miech C, Pauer H-U, He X, Schwarz TL. Presynaptic local signaling by a canonical wingless pathway regulates development of the drosophila neuromuscular junction. J Neurosci. 2008;28(43):10875-84.

241. Franco B, Bogdanik L, Bobinnec Y, Debec A, Bockaert J, Parmentier ML, et al. Shaggy, the homolog of glycogen synthase kinase 3, controls neuromuscular junction growth in drosophila. J Neurosci. 2004;24(29):6573-7.

242. Gögel S, Wakefield S, Tear G, Klämbt C, Gordon-Weeks PR. The drosophila microtubule associated protein Futsch is phosphorylated by shaggy/Zestewhite 3 at an homologous GSK3 $\beta$ phosphorylation site in MAP 1B. Mol Cell Neurosci. 2006:33(2):188-99.

243. McCabe BD, Marqués G, Haghighi AP, Fetter RD, Crotty ML, Haerry TE, et al. The BMP homolog Gbb provides a retrograde signal that regulates synaptic growth at the drosophila neuromuscular junction. Neuron. 2003;39(2):241-54.

244. Aberle H, Haghighi AP, Fetter RD, McCabe BD, Magalhães TR, Goodman CS. Wishful thinking encodes a BMP type II receptor that regulates synaptic growth in drosophila. Neuron. 2002;33(4):545-58.

245. McCabe BD, Hom S, Aberle H, Fetter RD, Marques G, Haerry TE, et al. Highwire regulates presynaptic BMP signaling essential for synaptic growth. Neuron. 2004;41(6):891-905.

246. Ball RW, Warren-Paquin M, Tsurudome K, Liao EH, Elazzouzi F, Cavanagh C, et al. Retrograde BMP signaling controls synaptic growth at the nmj by regulating trio expression in motor neurons. Neuron. 2010;27;66(4):536-49.

247. Goold CP, Davis GW. The BMP ligand Gbb gates the expression of synaptic homeostasis independent of synaptic growth control. Neuron. 2007:56(1): 109-23 [cited 2020 Jun 21]. Available from: /pmc/articles/PMC2699048/ ?report=abstract.

248. Hoover KM, Gratz SJ, Qi N, Herrmann KA, Liu Y, Perry-Richardson JJ, et al. The calcium channel subunit a2 $\delta$-3 organizes synapses via an activity-dependent and autocrine BMP signaling pathway. Nat Commun. 2019;10(1) [cited 2020 Jun 21]. Available from: https://pubmed.ncbi.nlm.nih.gov/31811118/.

249. James RE, Hoover KM, Bulgari D, McLaughlin CN, Wilson CG, Wharton KA, et al. Crimpy enables discrimination of presynaptic and postsynaptic pools of a BMP at the drosophila neuromuscular junction. Dev Cell. 2014;31(5): 586-98 [cited 2020 Jun 21]. Available from: https://pubmed.ncbi.nlm.nih. gov/25453556/.

250. Eaton BA, Davis GW. LIM Kinase1 controls synaptic stability downstream of the type II BMP receptor. Neuron. 2005;47(5):695-708.

251. Yoshihara M, Adolfsen B, Galle KT, Littleton JT. Retrograde signaling by Syt 4 induces presynaptic release and synapse-specific growth. Science (80- ). 2005;310(5749):858-63. 
252. Barber CF, Jorquera RA, Melom JE, Littleton JT. Postsynaptic regulation of synaptic plasticity by synaptotagmin 4 requires both C2 domains. J Cell Biol. 2009;187(2):295-310.

253. Yoshihara M, Littleton JT. Synaptotagmin functions as a calcium sensor to synchronize neurotransmitter release. Neuron. 2002;36(5):897-908.

254. Dani N, Broadie K. Glycosylated synaptomatrix regulation of trans-synaptic signaling. Dev Neurobiol. 2012;72(1):2-21.

255. Kamimura K, Ueno K, Nakagawa J, Hamada R, Saitoe M, Maeda N. Perlecan regulates bidirectional Wnt signaling at the drosophila neuromuscular junction. J Cell Biol. 2013;200(2):219-33.

256. Kamimura K, Odajima A, Ikegawa Y, Maru C, Maeda N. The HSPG Glypican regulates experience-dependent synaptic and behavioral plasticity by modulating the non-canonical BMP pathway. Cell Rep. 2019;28(12):31443156.e4 [cited 2020 Jun 21]. Available from: https://pubmed.ncbi.nlm.nih. gov/31533037/.

257. Bateman J, Shu H, Van Vactor D. The guanine nucleotide exchange factor trio mediates axonal development in the drosophila embryo. Neuron. 2000; 26(1):93-106.

258. Debant A, Serra-Pagès C, Seipel K, O'Brien S, Tang M, Park SH, et al. The multidomain protein trio binds the LAR transmembrane tyrosine phosphatase, contains a protein kinase domain, and has separate racspecific and rho-specific guanine nucleotide exchange factor domains. Proc Natl Acad Sci U S A. 1996;93(11):5466-71.

259. Friedman SH, Dani N, Rushton E, Broadie K. Fragile X mental retardation protein regulates trans-synaptic signaling in drosophila. Dis Model Mech 2013;6(6):1400-13.

260. Rohrbough J, Kent KS, Broadie K, Weiss JB. Jelly belly trans-synaptic signaling to anaplastic lymphoma kinase regulates neurotransmission strength and synapse architecture. Dev Neurobiol. 2013;73(3):189-208.

261. Rohrbough J, Rushton E, Woodruff E, Fergestad T, Vigneswaran K, Broadie K. Presynaptic establishment of the synaptic cleft extracellular matrix is required for post-synaptic differentiation. Genes Dev. 2007;21(20):2607-28.

262. Rohrbough J, Broadie K. Anterograde jelly belly ligand to Alk receptor signaling at developing synapses is regulated by mind the gap. Development. 2010;137(20):3523-33.

263. Rushton E, Rohrbough J, Deutsch K, Broadie K. Structure-function analysis of endogenous lectin mind-the-gap in synaptogenesis. Dev Neurobiol. 2012; 72(8):1161-79.

264. Fox MA, Sanes JR, Borza DB, Eswarakumar VP, Fässler R, Hudson BG, et al. Distinct target-derived signals organize formation, maturation, and maintenance of motor nerve terminals. Cell. 2007;129(1):179-93.

265. Muha V, Müller HAJ. Functions and mechanisms of fibroblast growth factor (FGF) signalling in Drosophila melanogaster. Int J Mol Sci. 2013; 14(3):5920-37.

266. Chang HC-H, Dimlich DN, Yokokura T, Mukherjee A, Kankel MW, Sen A, et al. Modeling spinal muscular atrophy in drosophila. PLoS One. 2008;3(9):e3209.

267. Chan YB, Miguel-Aliaga I, Franks C, Thomas N, Trülzsch B, Sattelle DB, et al. Neuromuscular defects in a drosophila survival motor neuron gene mutant. Hum Mol Genet. 2003:12(12):1367-76.

268. Kariya S, Park GH, Maeno-Hikichi Y, Leykekhman O, Lutz C, Arkovitz MS, et al. Reduced SMN protein impairs maturation of the neuromuscular junctions in mouse models of spinal muscular atrophy. Hum Mol Genet. 2008;17(16): 2552-69.

269. McNeill EM, Thompson C, Berke B, Chou VT, Rusch J, Duckworth A, et al. Drosophila enabled promotes synapse morphogenesis and regulates active zone form and function. Neural Dev. 2020;15(1):4.

270. Nesler KR, Sand RI, Symmes BA, Pradhan SJ, Boin NG, Laun AE, et al. The miRNA pathway controls rapid changes in activity-dependent synaptic structure at the Drosophila melanogaster neuromuscular junction. PLoS One. 2013;8(7):e68385.

271. Lahey T, Gorczyca M, Jia XX, Budnik V. The drosophila tumor suppressor gene $\mathrm{dlg}$ is required for normal synaptic Bouton structure. Neuron. 1994; 13(4):823-35.

272. Guan B, Hartmann B, Kho YH, Gorczyca M, Budnik V. The drosophila tumor suppressor gene, dlg, is involved in structural plasticity at a glutamatergic synapse. Curr Biol. 1996;6(6):695-706.

273. Van Vactor D, Wall DP, Johnson KG. Heparan sulfate proteoglycans and the emergence of neuronal connectivity. Curr Opin Neurobiol. 2006;16(1):40-51.

274. Lin T-Y, Huang C-H, Kao H-H, Liou G-G, Yeh S-R, Cheng C-M, et al. Abi plays an opposing role to $\mathrm{Abl}$ in drosophila axonogenesis and synaptogenesis. Development. 2009;136(18):3099-107.
275. Pawson C, Eaton BA, Davis GW. Formin-dependent synaptic growth evidence that Dlar signals via diaphanous to modulate synaptic actin and dynamic pioneer microtubules. J Neurosci. 2008;28(44):11111-23.

276. Goel P, Dufour Bergeron D, Böhme MA, Nunnelly L, Lehmann M, Buser C, et al. Homeostatic scaling of active zone scaffolds maintains global synaptic strength. J Cell Biol. 2019;218(5):1706-24.

277. Pandey UB, Nichols CD. Human disease models in. Pharmacol Rev. 2011 ; 63(2):411-36.

278. Reiter LT, Potocki L, Chien S, Gribskov M, Bier E. A systematic analysis of human disease-associated gene sequences in Drosophila melanogaster. Genome Res. 2001:11(6):1114-25.

\section{Publisher's Note}

Springer Nature remains neutral with regard to jurisdictional claims in published maps and institutional affiliations.
Ready to submit your research? Choose BMC and benefit from:

- fast, convenient online submission

- thorough peer review by experienced researchers in your field

- rapid publication on acceptance

- support for research data, including large and complex data types

- gold Open Access which fosters wider collaboration and increased citations

- maximum visibility for your research: over $100 \mathrm{M}$ website views per year

At BMC, research is always in progress.

Learn more biomedcentral.com/submissions 